\title{
Recent advances in unraveling the molecular mechanisms and functions of HOXA11-AS in human cancers and other diseases (Review)
}

\author{
CHENG WEI $^{1 *}$, LIANGJUAN ZHAO $^{2 *}$, HAO LIANG $^{1}$, YINGWEI ZHEN $^{3}$ and LEI HAN ${ }^{1}$ \\ ${ }^{1}$ Tianjin Neurological Institute, Key Laboratory of Post-Neuroinjury Neuro-Repair and \\ Regeneration in Central Nervous System, Ministry of Education and Tianjin City, Tianjin Medical University General Hospital, \\ Heping, Tianjin 300052; ${ }^{2}$ Tianjin Customs District China, Heping, Tianjin 300041; ${ }^{3}$ Department of Neurosurgery, \\ The First Affliated Hospital of Zhengzhou University, Zhengzhou, Henan 453002, P.R. China
}

Received June 15, 2019; Accepted January 24, 2020

DOI: $10.3892 /$ or.2020.7552

\begin{abstract}
A large number of previously published research articles have demonstrated that the expression levels of long noncoding RNAs (lncRNAs) are generally dysregulated, either through overexpression or underexpression, in cancer and other types of disease. As a recently discovered lncRNA, HOXA11 antisense RNA (HOXA11-AS) is able to serve as an oncogenic or tumor-suppressor gene and serves a vital role in the processes of proliferation, invasion, and migration of cancer cells. HOXA11-AS appears to be a major factor contributing to epigenetic modification, and exerts transcriptional, post-transcriptional, translational and post-translational regulatory effects on genes through a variety of mechanisms; for example, by competing endogenous RNA (ceRNA) and a molecular scaffold mechanism. A number of reports have demonstrated that HOXA11-AS functions as a protein scaffold for polycomb repressive complex 2 (PRC2), lysine-specific histone demethylase 1 (LSD1) and DNA methyltransferase 1 (DNMT1) to perform epigenetic modifications on chromosomes in the nucleus. Furthermore, HOXA11-AS is also located in the cytoplasm and can act as a ceRNA, which
\end{abstract}

Correspondence to: Dr Lei Han, Tianjin Neurological Institute, Key Laboratory of Post-Neuroinjury Neuro-Repair and Regeneration in Central Nervous System, Ministry of Education and Tianjin City, Tianjin Medical University General Hospital, 154 Anshan Road, Heping, Tianjin 300052, P.R. China

E-mail: superhanlei@hotmail.com

Dr Yingwei Zhen, Department of Neurosurgery, The First Affliated Hospital of Zhengzhou University, 1 Jianshe Road East, Zhengzhou, Henan 453002, P.R. China

E-mail: fcczhenyw@zzu.edu.cn

*Contributed equally

Key words: long noncoding RNA, HOXA11 antisense RNA, competing endogenous RNA, molecular scaffold sponges miRNAs. In addition, HOXA11-AS may be useful as a biomarker for the diagnosis and prognosis of cancer. In the present review article, the clinical value, phenotype and mechanism of HOXA11-AS in a variety of tumors types are briefly summarized, as well as its clinical value in certain additional diseases. The perspective of the authors is that HOXA11-AS may represent an effective tumor marker and therapeutic target for cancer diagnosis and therapy.

\section{Contents}

1. Introduction

2. Discovery and description of HOXA11-AS

3. Conclusion

\section{Introduction}

With the incidence of cancer and mortality rates rising rapidly worldwide, cancer is anticipated to become both the most significant obstacle to extending life expectancy, and the major cause of death worldwide. Cancer has already become the first or second main cause of mortality in 91 of 172 countries for persons aged 70 or less, and is ranked third or fourth in a further 22 countries, according to data published by the World Health Organization (WHO) in 2015 (1). During 2018, over 18.1 million new cases of cancer and 9.6 million cancer deaths were estimated to have occurred worldwide. For both the sexes, in 2018 Asia accounted for nearly one-half of all cancer cases, and more than one-half of cancer-associated deaths globally (1). Despite improvements in radiotherapy, chemotherapy and surgical treatment technologies, various types of cancer remain very difficult to treat, such as gastric cancer (GC), non-small cell lung cancer (NSCLC) and bladder cancer (BC) $(2,3)$. Therefore, study of the pathogenesis and therapeutic targets of cancer is imperative.

The transcriptional background of all organisms has been shown to be much more complicated than was at first envisioned, since various protein-coding RNAs and noncoding 
RNAs (ncRNAs) are extensively transcribed from large portions of genomic sequences $(4,5)$. Thus, to resolve these problems, a clear understanding of the intracellular transcriptional environment must be obtained. Benefiting from the development of new generation sequencing technologies, it has been shown that, in humans, over $70 \%$ of the genome sequence is transcribed. Among these transcripts, less than $2 \%$ of the transcripts contain protein-coding RNAs, whereas the remaining transcripts produce ncRNAs (6-9). Previously, it was considered that the products of most non-protein-coding genes were without any function, simply produced during the process of gene transcription. However, with the development of research in this area, there is a new understanding that the products of these non-protein-coding genes are involved in the regulation of a variety of biological processes in cells (6-9). At present, ncRNAs are a hot research topic in the life sciences.

NcRNAs comprise regulatory RNAs (for instance, miRNAs) and structural RNAs [such as small nuclear RNAs (snRNAs), ribosomal RNAs (rRNAs) and transfer RNAs (tRNAs)] (10). Thanks to recent advances in the acquisition of genome and transcriptome sequencing data, the catalogue of regulatory molecules now contains numerous long noncoding RNAs (IncRNAs), a loosely classified group of long RNA transcripts that lack protein-coding function $(11,12)$. As early as 1991, it was found that X-inactive specific transcript (XIST) is involved in regulating $\mathrm{X}$ chromosome inactivation, providing an initial insight into lncRNA functionality $(13,14)$. At present, 96,308 lncRNA genes as well as 172,216 lncRNA transcripts, have been identified in humans [data from NONCODE, the ncRNA database including sequence, documentation and analysis (http://www.bioinfo.org/noncode/)], which influence a great variety of cellular biological processes. lncRNAs were undervalued for a long time, being considered as merely transcriptional 'garbage' across the entire length of the genome (15). However, the expression of lncRNAs is now known to be dysregulated in a great majority of tumor types, including lung cancer (16), hepatocellular carcinoma (HCC) (17), glioma (18), colorectal cancer (CRC) (19), breast cancer (BC) (20), osteosarcoma (21), ovarian cancer (22), gastric cancer (GC) (23), and esophageal squamous cell carcinoma (ESCC) (24). Emerging studies have now shown that lncRNA has a vital role in a wide variety of cellular biological processes, including cellular differentiation, cell cycle, proliferation, migration, metabolism, as well as apoptosis, especially in tumor cells $(25,26)$. These findings suggest that IncRNA functions as an oncogene or tumor suppressor through interaction with other biomolecules or via chromatin modifications (27).

lncRNAs are able to interfere in numerous cellular processes, including chromatin organization, transcription complex recruitment, post-transcriptional regulation, translation, and post-translational processes $(12,28,29)$. Several of the main mechanisms of lncRNAs are discussed below.

Chromatin organization. The dosage compensation effect of the $\mathrm{X}$ chromosome in mammals provides a striking instance of IncRNA-mediated chromatin regulation. Xist, one of the first functionally annotated lncRNAs, regulates dosage compensation in female mammals by localizing to the $\mathrm{X}$ chromosome, and recruiting various factors directly or indirectly to accomplish X chromosome inactivation (XCI) (30). In brief, dosage compensation refers to the process by which the gene expression level of the two $\mathrm{X}$ chromosomes in female cells is made equivalent to the one $\mathrm{X}$ chromosome in male cells. The expression of IncRNA Xist in female cells is from one of the two X chromosomes, which subsequently changes the chromatin structure of the whole chromosome, whereby most of the genes in the inactive $\mathrm{X}$ chromosome are silenced during transcription (31-33). Significantly, Xist can interact with polycomb repressive complex 2 (PRC2) via a structural domain called Repeat A, resulting in PRC2 and its cognate histone marker histone H3 lysine 27 trimethylation (H3K27me3) being located on the inactive $\mathrm{X}$ chromosome. IncRNAs can also recruit PRC2 to modulate distal genes throughout the genome (34). In addition, IncRNAs expressed only in embryonic stem cells are able to directly interact with chromatin to regulate gene expression and maintain pluripotency (35). The interaction between DNA and lncRNA is achieved either via sequence complementation or via combination in helical structures (28). Therefore, IncRNAs are associated with organization of the nuclear architecture and the general structuring of the genome, thereby affecting the expression of related genes (36).

Transcriptional regulation. At the transcriptional level, lncRNA is often used as a molecular scaffold to recruit two or more proteins to the promoter regions of their target genes, and modulates the transcription of the target genes (37-39). These proteins include zinc-finger proteins, DNA methyltransferases, transcription factors (TFs), and other transcriptional regulators (40). Furthermore, IncRNA can act as an adaptor to recruit associated proteins into discrete complexes (41). For instance, the IncRNA HOTAIR synchronously binds both PRC2 and LSD1-CoREST complexes through specific structural domains of the RNA (42). This interaction effectively harmonizes the methylation of H3K27 and demethylation of H3K4me2, guaranteeing that gene silencing occurs. Functioning as a molecular scaffold is among the primary mechanisms by which HOXA11-AS functions.

Post-transcriptional regulation. At the post-transcriptional level, IncRNAs operate in diverse ways to affect miRNAs and mRNAs $(43,44)$. First, lncRNAs are hypothesized to act as competing endogenous RNA (ceRNA), or as 'RNA sponges', which are able to interact with miRNAs, thereby blocking the interaction between miRNAs and mRNAs, thus decreasing their regulatory impact on target mRNAs $(45,46)$. For example, HOXA11-AS serves as a ceRNA to modulate the expression level of the transcription factor Spl by sequestering miR-124. Findings demonstrated that improvements in cell invasion and proliferation mediated by HOXA11-AS were reversed by miR-124 (47). Secondly, IncRNAs can be precursors of miRNAs, which are able to modulate different processes in miRNA production and have microprocessor activity to complete primary transcripts via a mechanism independent of polyadenylation (48). For instance, lncRNA LOC554202 was shown to be the putative precursor of miR-31, exerting an important role in preventing metastasis of BC (49). In addition, the maturation of miR-145 can be hindered by lncRNA colon cancer-associated transcript 2 (CCAT2) via the repression 
of Dicer cleavage and cytoplasmic export (50). Moreover, lncRNAs also affect alternative splicing and the stability of mRNA. For example, first apoptosis signal (Fas)-antisense IncRNA-SAF complex is able to combine with the human splicing factor SPF45, resulting in removal of exon 6 during Fas splicing and the production of a soluble Fas protein that serves to inhibit Fas/Fas ligand (FASL)-mediated apoptosis in different human cell lines (51). In addition, lncRNA PDCD4-AS1 stabilizes programmed cell death 4 (PDCD4) RNA via formation of an RNA duplex that dictates the mutual effect between RNA decay promoting factors and PDCD4 RNA, in human BC (52).

Recently, numerous studies $(19,53)$ have reported that exosomes can function as autocrine or paracrine factors to influence the significant biological functions that mediate intercellular interactions. An increasing amount of evidence has shown that cancer cells are able to release exosomes, and exosome-transmitted lncRNAs are able to promote tumor metastasis, angiogenesis and drug resistance. For example, lncRNA-APC1 is able to inhibit the production of exosomes, and reduce their stability by directly binding Rab5b mRNA, thereby inhibiting the growth, metastasis and tumor angiogenesis of CRC cells (19). Additionally, Qu et al (53) found that bioactive lncARSR [IncRNA activated in renal cell carcinoma (RCC) with sunitinib resistance] can be integrated into exosomes and delivered to sensitive cells in RCC. When exosomes containing lncARSR reached the sensitive RCC cells, IncARSR was released into the cytoplasm. The expression of the receptor tyrosine kinases AXL and c-MET in RCC cells was promoted by lncARSR competitively binding miR-34/miR-449, thus promoting sunitinib resistance. AXL and c-MET are responsible for IncARSR-mediated sunitinib resistance in RCC (53).

Translational process. In addition to the abovementioned effects, IncRNAs are also able to promote or inhibit the translational process. For example, dopaminergic neurons specifically express ubiquitin carboxy-terminal hydrolase L1 (Uchl1). Uchl1 can be modulated by its antisense transcript (AS Uchl1), which binds polysomes through its repetitive domain termed 'SINEB2' to facilitate cap-independent translation (54). Furthermore, IncRNA-p21, a post-transcriptional modulator, passively modulates translation of the transcripts of the transcription factor JUNB and $\beta$-catenin through incomplete complementary base pairing at diverse sites in the coding and non-coding regions [both 5'- and 3'-untranslated regions (UTRs)] of JUNB ( 8 sites) and $\beta$-catenin (15 sites) mRNA, leading to the formation of an lncRNA-p21-mRNA complex. The communication between mRNAs and Fragile X mental retardation protein (FMRP), as well as the translational repressor RCK, may be improved by the lncRNA-p21-mRNA complex, resulting in suppression of the translation target transcripts via the reduction of ribosome drop-off and polysome sizes (54-56).

Post-translational modification. IncRNAs not only regulate the translational process, but also modify proteins produced after translation via mechanisms such as phosphorylation and ubiquitination. The activity and stability of a protein can be altered through these modifications (57). For instance, the
lncRNA SLCO4A1-AS1 interacts with $\beta$-catenin to improve its stability through weakening the communication between glycogen synthase kinase $\beta$ (GSK $\beta$ ) and $\beta$-catenin, restricting its phosphorylation and leading to $\mathrm{Wnt} / \beta$-catenin signaling activation in CRC (58). In addition, the lncRNA SNHG15 can sustain Slug stability by inhibiting the interaction between Slug and $\beta$-transducin repeat containing (BTRC) E3 ubiquitin protein ligase, blocking BTRC-mediated Slug ubiquitination in colon cancer (59).

It may be concluded that, from the chromatin level to transcription, post-transcription, translation and post-translational regulation, IncRNAs fulfill important roles in all aspects of cell physiology.

\section{Discovery and description of HOXA11-AS}

IncRNA HOXA11-AS, located in the HOXA gene cluster, has been reported to exert an impact on the occurrence of variety of human diseases and their subsequent development (60). HOXA11-AS is located on chromosome 7p15.2, and is referred to as HOXA11AS, HOXA11-AS1, HOXA11S, HOXA-AS5 or NCRNA00076. The chromosomal localization and secondary structure of HOXA11-AS are shown in Fig. 1. The length of the HOXA11-AS gene is 3,885 bp, whereas the HOXA11-AS transcript is 1628 bp in length (61). HOX genes are organized into four clusters (A, B, C and D) on four diverse chromosomes, and HOXA is a member of the homeobox (HOX) family in the human genome $(62,63)$. The HOXA gene has a sense strand and an antisense strand that include protein-coding genes and ncRNA genes, respectively. The 5'-region of the HOXA gene refers to the direction of the sense strand relative to the direction of protein coding genes, and the most abundant protein-coding gene of the 5'-region is HOXA13. Furthermore, a further three protein-coding genes, HOXA9, HOXA10 and HOXA11, and 3 lncRNAs, HOXA10-AS, HOXA11-AS and HOTTIP, are located in the 5'-region $(64,65)$. HOXA11-AS is a novel lncRNA that functions as an oncogene or tumor-suppressor gene in diverse types of tumor. For example, HOXA11-AS can serve as an oncogene in non-small cell lung cancer (NSCLC), HCC, glioma, BC, GC, renal cancer (RC), uveal melanoma (UM), laryngeal squamous cell carcinoma (LSCC), cervical cancer (CC), ESCC and osteosarcoma. By contrast, HOXA11-AS functions as a tumor suppressor in epithelial ovarian cancer (EOC) $(7,66,67)$.

The subsequent sections of this review provide an overview of the clinical significance, biological functions, and molecular mechanisms of HOXA11-AS in tumors and several other diseases types, with the aim of intuitively understanding the role of HOXA11-AS in the occurrence and development of human disease.

\section{HOXA11-AS in cancer}

Nonsmall-cell lung cancer (NSCLC). Lung cancer is the primary cause of cancer mortality and the most commonly occurring type of cancer worldwide $(68,69)$. No fewer than 2.1 million people are diagnosed with lung cancer annually (1). Histologically, lung cancer can be divided into small cell lung cancer (SCLC) and NSCLC. Approximately 80-85\% of newly diagnosed cases of lung cancer belong to the NSCLC type $(70,71)$. Numerous 1 ncRNAs, including HOXA11-AS, 
A

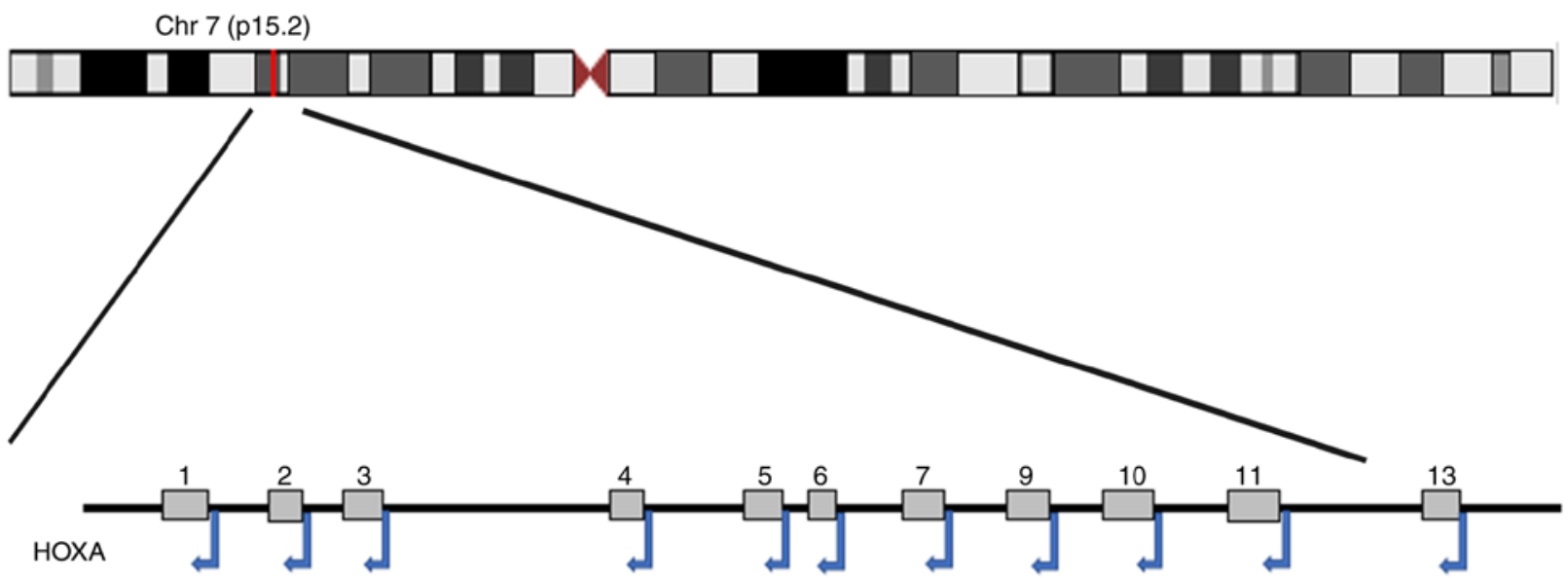

Human
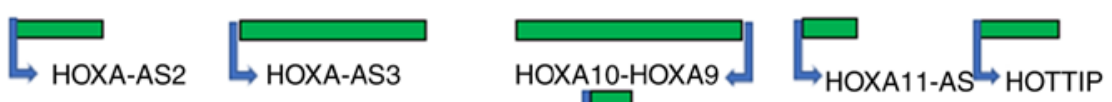

B

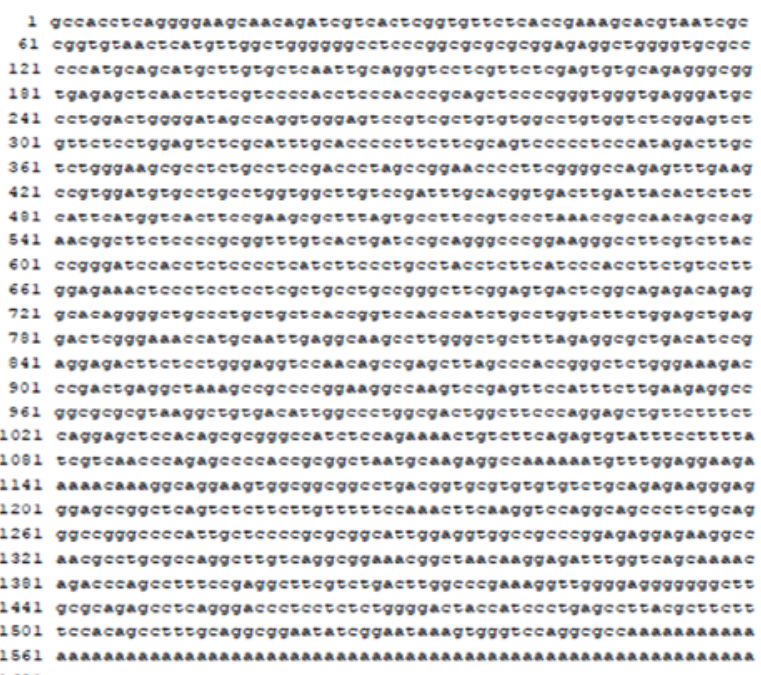

C

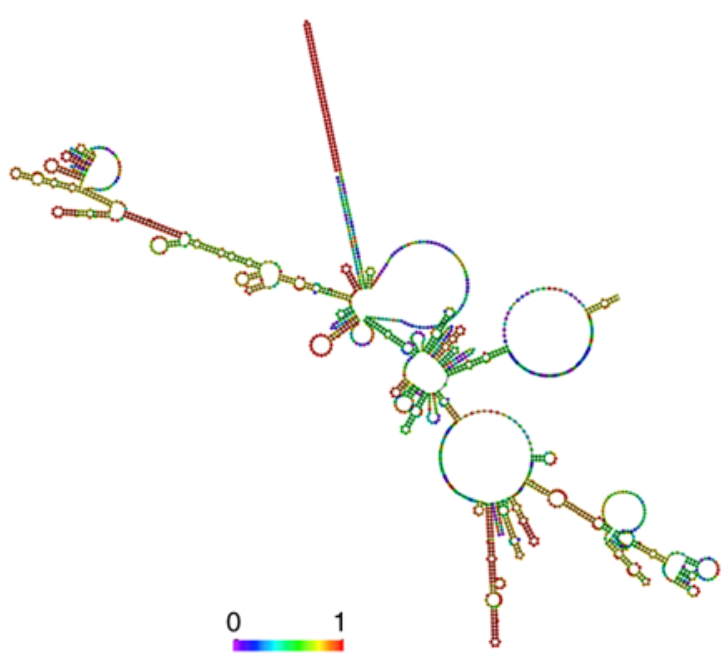

Figure 1. The diagram shows (A) the chromosomal localization of HOXA11-AS and its position in the HOXA family. Also shown are (B) the nucleotide sequence and (C) its secondary structure. HOXA11-AS, HOXA11 antisense RNA.

have been shown to have significant roles in NSCLC. Zhang et al $(73,74)$ reported that the expression of HOXA11-AS is higher in both squamous cell carcinoma (SCC) and lung adenocarcinoma (LUAD) compared with that in normal lung tissues, and HOXA11-AS knockdown suppresses tumorigenesis, angiogenesis, proliferation, migration and invasion of NSCLC cells, inducing apoptosis by impeding the cell cycle at the G0/G1 or the G2/M phase. Moreover, Chen et al (75) identified that high levels of HOXA11-AS predict poor prognosis in patients with NSCLC. Furthermore, Yu et al (48) demonstrated that the expression level of HOXA11-AS is associated with lymph node metastasis and tumor size. Zhao et al (76) also reported that high levels of HOXA11-AS are associated with poor prognosis.

Mechanistically, Zhang et al (72-74) revealed that HOXA11-AS expression is negatively correlated with dedicator of cytokinesis 8 (DOCK8) in SCC and LUAD. Those authors conjectured that HOXA11-AS could have an oncogenic role in the development and progression of NSCLC by modulating various pathways, such as the transforming growth factor (TGF)- $\beta$ pathway, the phosphoinositide 3-kinase (PI3K)-Akt pathway and the Hippo signaling pathway, and genes, such as DOCK 8 gene. In other studies, the same authors demonstrated that the expression of HOXA11-AS co-expressed genes in NSCLC may be partly regulated by the NSCLC pathway and that HOXA11-AS could affect various biological processes of NSCLC via regulation of the expression of miR-642b-3p by targeting the expression of phosphodiesterase 4D (PDE4D) or other target genes (72-74). Additionally, Chen et al (75) found that HOXA11-AS interacts with DNA (cytosine-5)-methyltransferase 1 (DNMT1) and enhancer of zeste homolog 2 (EZH2), recruiting these proteins to the promoter regions of miR-200b and mediating methylation silencing of miR-200b in NSCLC cells, a process that promotes both NSCLC cell epithelial-mesenchymal transition (EMT) via regulation of the protein levels of E-cadherin, N-cadherin, Snail1/2 and ZEB1/2 and tumor progression. Yu et al (48) revealed 
A

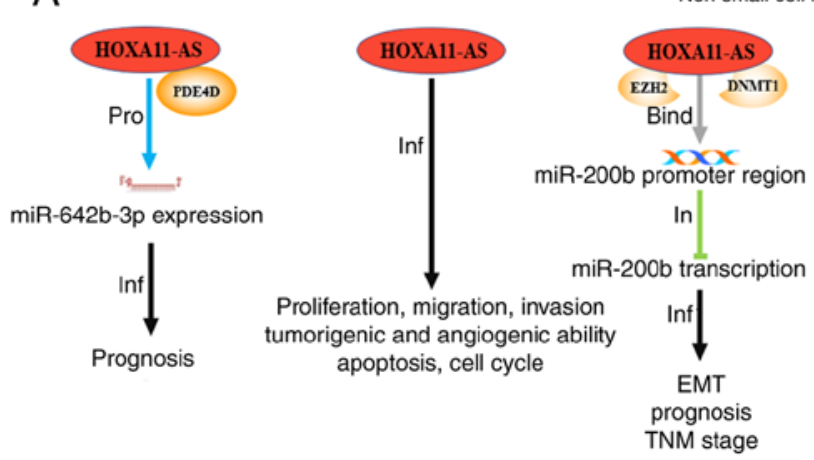

Non-small-cell lung cancer (NSCLC)

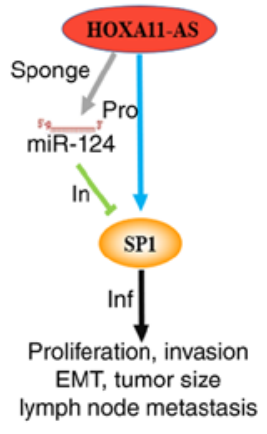

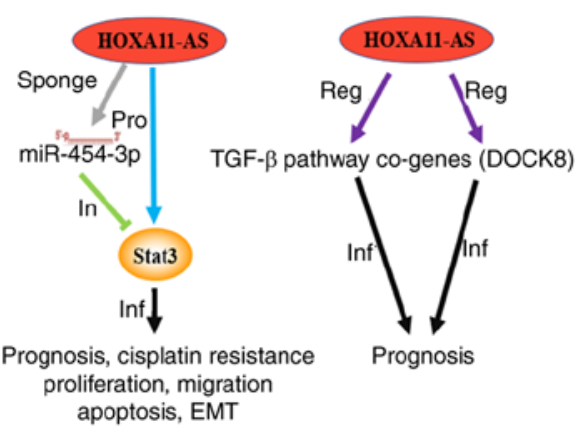

B

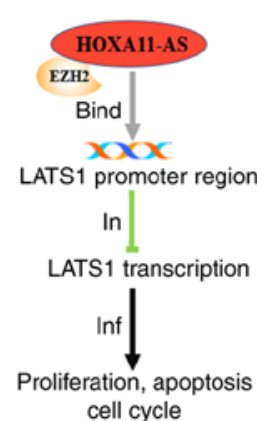

Hepatocellular carcinoma (HCC)

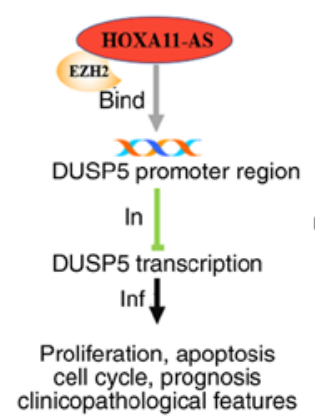

C

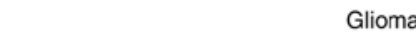

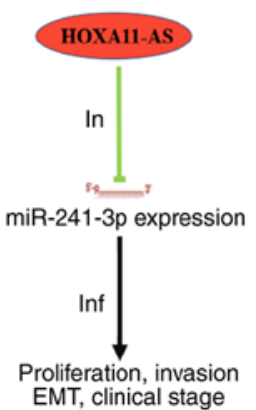
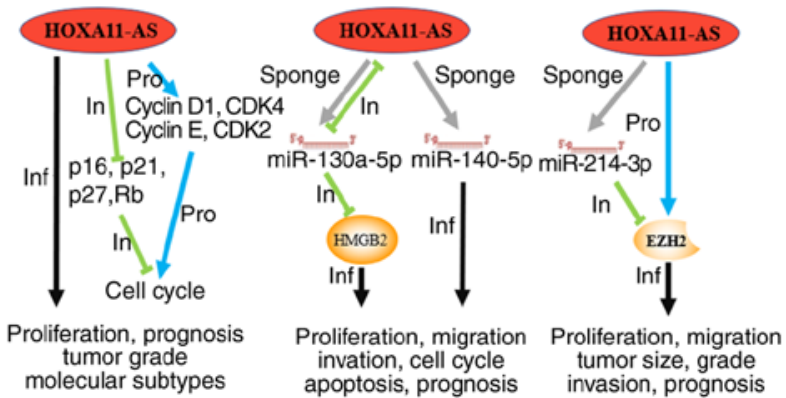

Glioma

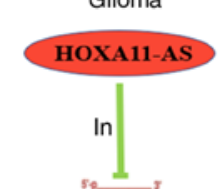

miR-124-3p expression

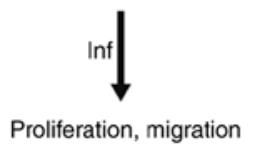
invasion, apoptosis
D

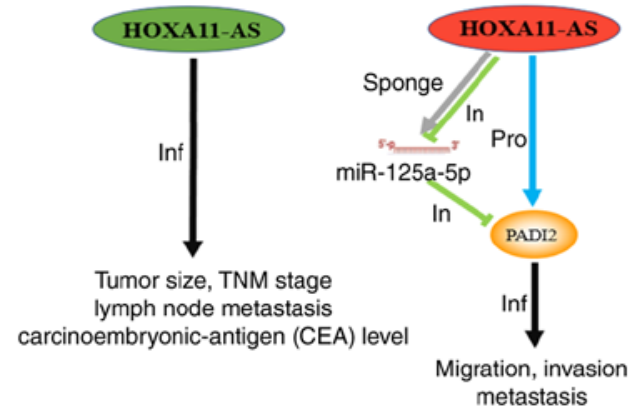

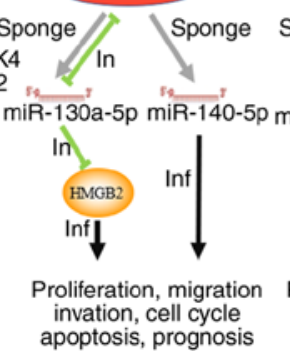

Breast cancer $(\mathrm{BC})$
E

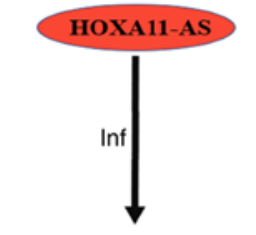

Proliferation, metastasis cell cycle, tumor size TNM stage migration, invasion colony formation ability
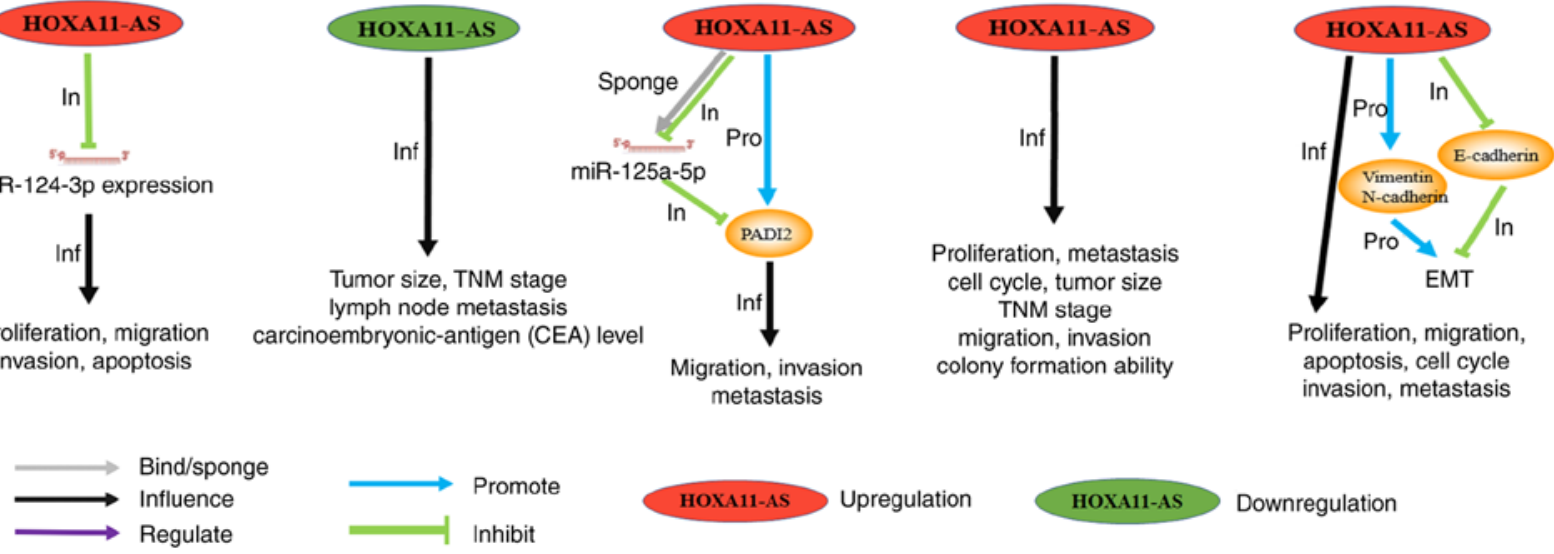

Downregulation

Figure 2. Schematic diagram that introduces in detail the molecular mechanisms, clinical values and cell phenotypes affected by HOXA11-AS in different tumor types, including (A) NSCLC, (B) HCC, (C) glioma, (D) CC, and (E) BC. 'Upregulation'/'downregulation' indicates that the expression level of HOXA11-AS in such a tumor was increased/decreased compared with normal tissues. The gray arrows ('bind'/'sponge') indicate that HOXA11-AS binds to the promoter region of a gene or, as a sponge, binds to a miRNA. The black arrows ('Inf') indicate that HOXA11-AS affects the phenotypes and the clinical characteristics of the cancer under consideration. The blue ('Pro')/green ('In') arrows indicate the promoting or inhibitory effects on the downstream genes, respectively. The purple arrows ('Reg') indicate the regulatory effects on the downstream pathway. NSCLC, non-small cell lung cancer; HCC, hepatocellular carcinoma; CRC, colorectal cancer; BC, breast cancer; HOXA11-AS, HOXA11 antisense RNA.

that HOXA11-AS acts as a ceRNA to positively modulate the expression of transcription factor Sp1 by sequestering miR-124, a process that can inhibit cell proliferation and the invasion-promoting effects of HOXA11-AS. Futhermore, those authors found that HOXA11-AS can serve as an oncogene by promoting EMT via regulation of the protein levels of E-cadherin, $\beta$-catenin, vimentin and the EMT-mediating transcription factors Slug and Snail in NSCLC (48). Zhao et al (76) discovered that, in human LUAD cells, HOXA11-AS can function as a ceRNA to facilitate cisplatin tolerance through the miR-454-3p/Stat3 pathway (the abovementioned mechanisms are shown in Fig. 2A). Recent findings (77) have shown that membrane-bound extracellular vesicles, especially exosomes, serve significant roles as mediators for communication among different tissues and organs. Exosomes have a vital role in signal transduction among cells, and a wide range of biological functions. Wu et al (77) reported that high expression levels of HOXA11-AS in exosomes are closely associated with smoking and NSCLC in lung tissues. These findings indicate that HOXA11-AS has several functions associated with oncogenesis, regulating various physiological activities in NSCLC. These findings 
shed light upon the effects of HOXA11-AS on the progression of NSCLC and indicate that HOXA11-AS is a potential target for future treatment of NSCLC.

Hepatocellular carcinoma. Hepatocellular carcinoma (HCC), which accounts for $90 \%$ of cases of liver cancer, is the fifth most frequent cancer in men and the ninth in women worldwide $(78,79)$. The mortality rate of HCC ranks second in the world $(80,81)$. Recently, cancer-associated studies focused on lncRNAs have demonstrated that a considerable number of $\operatorname{lncRNAs}$ are involved in the progression of HCC (82-84). Previous studies revealed that HOXA11-AS is overexpressed in HCC cells and tissues (82-84). Liu et al (82) found that high expression levels of HOXA11-AS are significantly correlated with vascular invasion, cirrhosis, tumor size and Edmondson grade. The overall survival (OS) rate of patients with high levels of HOXA11-AS expression is markedly shorter compared with those with lower levels of HOXA11-AS expression. Overexpression of HOXA11-AS promotes cell cycle progression, proliferation, invasion, and EMT, as well as repressing apoptosis in HCC cells.

$\mathrm{Yu}$ et al (83) reported that HOXA11-AS recruits PRC2 to the promoter region of large tumor suppressor 1 (LATS1) to obstruct its transcription, thereby promoting HCC growth and inhibiting apoptosis and cell cycle progression at the G0/G1 phase. The results from flow cytometry experiments indicated that the cell cycle progression of HCC cells was stalled at the G0/G1 phase when HOXA11-AS RNAi was transfected into HCC cells (83). Zhan et al (84) showed that the overexpression of HOXA11-AS is able to facilitate HCC proliferation and invasion, and induce EMT by repressing the expression of miR-214-3p. In addition, these authors demonstrated that the expression of miR-214-3p in early clinical stages (I-II) was higher than that in advanced clinical stages (III-IV). Furthermore, Liu et al (82) reported that HOXA11-AS recruits EZH2 to the promoter region of dual specificity protein phosphatase 5 (DUSP5), thereby inhibiting the transcription of DUSP5, which is a downstream target of HOXA11-AS and can function as a tumor suppressor gene. HOXA11-AS performs an oncogenic role in HCC by interacting with PRC2 (the abovementioned mechanisms are shown in Fig. 2B). HOXA11-AS may function as an oncogene in HCC development. The interaction between HOXA11-AS and LATS1, DUSP5 or miR-214-3p may supply novel prognostic markers and therapeutic targets for HCC.

Glioma. Glioma, accounting for approximately $80 \%$ of primary malignant brain tumors, is the most aggressive primary tumor of the nervous system. Effective treatment of gliomas is very difficult, particularly glioblastomas (GBMs, also known as grade IV astrocytomas), with a median survival time for patients of less than 15 months using standard therapy (85-88). To date, although many studies have been focused on seeking improvements in diagnosis and treatment, the trend of poor prognosis has not been reversed (89). Among the numerous biomolecules involved in the occurrence and development of glioma, IncRNAs have attracted sustained attention due to their abnormal expression during tumorigenesis. Wang et al (90) discovered that high levels of HOXA11-AS expression are closely correlated with OS in high-grade glioma, and
HOXA11-AS may be an independent prognostic factor for GBM. HOXA11-AS overexpression might occur during initial gliomagenesis and increased levels might be maintained in higher grades of gliomas. Those authors reported that the expression levels of HOTTIP, HOXA9, HOXA10, and HOXA13 are prominently correlated with HOXA11-AS expression, and HOXA11-AS can alter the expression of cell cycle-associated proteins, thus regulating cell cycle progression. Moreover, Cui et al (91) and Xu et al (92) found that high expression levels of HOXA11-AS are correlated with decreased survival time and poorer prognosis compared with patients with lower HOXA11-AS expression. In addition, $\mathrm{Xu}$ et al (93) found that the overexpression of HOXA11-AS is associated with advanced stages of glioma and poor prognosis. Authors of that study reported that knocking down the expression of HOXA11-AS leads to suppression of the proliferation, migration, and invasion rates of glioma cells in vitro, with the consequent further enhancement of cell cycle arrest at the G0/G1 stage and improved apoptotic responses.

Cui etal (91) showed that miR-140-5p is able to directly target the 3'-UTR of HOXA11-AS, and the effects of HOXA11-AS knockdown are shown to be reversed by an miR-140-5p inhibitor, as determined by its effects on cell cycle arrest, proliferation and apoptosis. Xu et al (92) demonstrated that HOXA11-AS functions as a ceRNA by sponging miR-214-3p, which can directly target EZH2 and suppress its mRNA transcriptional level. It was thereby confirmed that HOXA11-AS may serve in an oncogenic role by regulating the miR-214-3p/EZH2 pathway. Yang et al (94) found that HOXA11-AS leads to a marked increase in proliferation, invasion and migration rates, while inhibiting apoptosis by absorbing miR-124-3p in glioma cells. Furthermore, Xu et al (93) found that HOXA11-AS can exert its oncogenic role by directly binding to miR-130a-5p as a ceRNA, which inhibits the inhibitory effect of miR-130a-5p on HMGB2 expression. HMGB2 has been demonstrated to be involved in several diseases, such as sepsis, arthritis and cancer (the abovementioned mechanisms are shown in Fig. 2C). The above results suggest that HOXA11-AS may be an oncogene participating in the prognosis and treatment response of specific GBM subtypes.

Colorectal cancer. Colorectal cancer (CRC) ranks third among the most common types of cancer in men, and second among women worldwide, with $\sim 55 \%$ of CRC cases occurring in developed countries $(95,96)$. The incidence of CRC has rapidly increased in China, and in 2011, it was shown to be the second most common cause of cancer-associated mortality (97). Although recent advances have been made in the diagnosis and treatment of CRC in recent years, the prognosis of patients diagnosed with CRC remains poor; in fact, the 5 -year survival rate in patients with metastatic CRC has been shown to be less than $20 \%(98,99)$. Li et al $(100)$ reported that HOXA11-AS is downregulated in CRC cell lines and tissues, and low expression levels of HOXA11-AS are associated with advanced tumor-lymph node-metastasis (TNM) stages, lymphatic metastasis, large tumor size and elevated levels of carcinoembryonic antigen (CEA). Authors of that study also showed that the IncRNA HOXA11-AS may distinguish CRC tissue from noncancerous tissue, and they further explored the correlation between HOXA11-AS and lymph node 
metastasis. Moreover, Chen et al (101) reported that the level of HOXA11-AS was markedly upregulated in CRC patients with liver metastasis, and the migration and invasion of CRC cells was facilitated by HOXA11-AS. In addition, Chen et al (101) found that HOXA11-AS can act as a ceRNA sequestering miR-125a-5p to modulate the expression of protein-arginine deiminase type-2 (PADI2), which was shown to facilitate metastasis and the invasion of CRC (the abovementioned mechanisms are shown in Fig. 2D). Consequently, a novel HOXA11-AS/miR-125a-5p/PADI2 pathway, involved in CRC liver metastasis, was identified. Taken together, these results demonstrated that HOXA11-AS is a potential biomarker and molecular therapy target in CRC.

Breast cancer. Breast cancer (BC) is one of the most frequent causes of cancer-associated mortality in women worldwide $(102,103)$. Although great progress has been made in earlier diagnosis of this disease and in the effective of systemic therapies, the overall prognosis of $\mathrm{BC}$ remains unsatisfactory. In particular, distant metastasis is a barrier for successful treatment (104-106). Su and Hu (107) discovered that IncRNA HOXA11-AS is overexpressed in human BC, and the expression of HOXA11-AS is markedly associated with metastasis, tumor size and TNM staging. Clinical statistics revealed that the expression of HOXA11-AS was correlated with Ki-67 protein and human epidermal growth factor receptor (HER2), but not with estrogen receptor (ER) or progesterone receptor (PR). Their results indicated that decreased expression levels of HOXA11-AS in human BC led to suppression in the rates of cell proliferation, migration and invasion, and cell cycle arrest at the G0/G1 phase. Li et al (108) also reported that low levels of HOXA11-AS expression inhibited cell proliferation and induced tumor cell apoptosis by inducing cell cycle arrest at the G0/G1 stage. By contrast, high levels of HOXA11-AS expression facilitated metastasis and invasion both in vitro and in vivo by exerting an influence on EMT in BC (the abovementioned mechanisms are shown in Fig. 2E). Note that the above articles $(107,108)$ only determined the involvement of HOXA11-AS in these processes; the specific mechanisms have yet to be properly elucidated. These studies, however, have confirmed that HOXA11-AS exerts carcinogenic effects in $\mathrm{BC}$, thereby providing some novel insights for even earlier diagnosis in the future, and for the therapy of $\mathrm{BC}$.

Gastric cancer. Gastric cancer (GC) ranks the fifth among the most common types of cancer, and is the third leading cause of cancer mortality (109). GC is more common in men: The mortality rate in men is 2-fold higher compared with women (1). In men, GC is the most commonly occurring gastrointestinal malignancy in East Asia, the most common cancer in several Western Asian countries and the main cause of cancer deaths $(110,111)$. Despite advances in surgical techniques and the successful development of targeted drugs, the 5-year OS rate, however, remains unsatisfactory, and the majority of patients are diagnosed with advanced cancer along with lymphatic metastasis (98). Sun et al (112) reported that HOXA11-AS is significantly upregulated in GC tissues. High levels of HOXA11-AS expression are closely related to poor differentiation, larger tumor size, lymph node metastasis and advanced pathological stage in GC. Researchers also found that progression-free survival (PFS) and OS rates in excess of 3 years in the group with high levels of HOXA11-AS expression were lower compared with the group with low levels of HOXA11-AS expression. HOXA11-AS overexpression leads to increased rates of cell growth, migration and invasion, and inhibition of apoptosis in GC. By contrast, Liu et al (113) reported that HOXA11-AS knockdown induces G0/G1 phase arrest in GC cells and decreases GC cell metastasis, migration and invasion, both in vitro and in vivo.

In terms of the underlying mechanism, Sun et al (112) demonstrated that HOXA11-AS acts as a protein scaffold to recruit EZH2, accompanied by DNMT1 or LSD1. In addition, HOXA11-AS functions as a miR-1297 sponge, thereby regulating the translation of EZHZ, a direct miR-1297 target. Knockdown of HOXA11-AS increases the expression of the tumor suppressors, serine protease 8 (PRSS8) and Krüppel-like Factor 2 (KLF2), leading to the promotion of cell proliferation and invasion and inhibiting apoptosis in GC cells. Those authors reported that EZH2 can directly bind to the promoter regions of PRSS8 and KLF2 and DNMT1 can directly bind to the promoter region of KLF2 to stimulate $\mathrm{H} 3 \mathrm{~K} 27$ me3 modifications. LSD1 is also able to directly bind to the promoter region of PRSS8 to mediate H3K4 demethylation. Knockdown of HOXA11-AS suppresses the binding capability of DNA with several chromatin modification factors (namely, PRC2, LSD1 and DNMT1). Moreover, Sun et al (112) identified the potential regulator E2F1, which can directly bind to the promoter region of HOXA11-AS and regulate the transcription of HOXA11-AS. In addition, HOXA11-AS can function as an oncogene by regulating the miR-1297/EZH2 and HOXA11-AS-EZH2/DNMT1/LSD1-KLF2/PRSS8 pathways to promote GC cell proliferation, migration and invasion and inhibit apoptosis. Liu et al (113) identified that HOXA11-AS enhances $\beta$-catenin transcription by interacting with WD repeat-containing protein 5(WDR5), and p21 transcription is subsequently inhibited via binding with EZH2. In addition, HOXA11-AS can interact with double-stranded RNA-binding protein staufen homolog 1 (STAU1) to promote KLF2 mRNA degradation. These findings revealed thatHOXA11-AS may serveas anoncogenebymodulating the HOXA11-AS-WDR5/EZH2/STAU1- $\beta$-catenin/p21/KLF2 pathway (Fig. 3A). Taken together, these results have revealed that HOXA11-AS can function as an oncogene in GC cells, further elucidating the role of HOXA11-AS in promoting better diagnosis of the disease, and developing further how lncRNA may be used in treatments of GC.

Renal cancer. Clear cell renal cell carcinoma (ccRCC) is a common malignant tumor of the urinary system, accounting for $>80 \%$ of all types of RC (114). No fewer than 209,000 new cases of ccRCC are reported each year, and among these cases, approximately $25-30 \%$ of the patients present with distant metastasis and $40 \%$ of patients have local recurrence after the initial diagnosis $(115,116)$. The biological behavior of ccRCC is extremely complex and the underlying molecular mechanisms have yet to be fully elucidated, factors which explain how prognosis is both poor and difficult to predict (117). Recently, Yang et al (118) found that HOXA11-AS was clearly upregulated in ccRCC cell lines and tissues, and high HOXA11-AS expression levels were very closely correlated with lymph node metastasis, tumor stage and advanced clinical stage. Downregulation of the HOXA11-AS transcript 


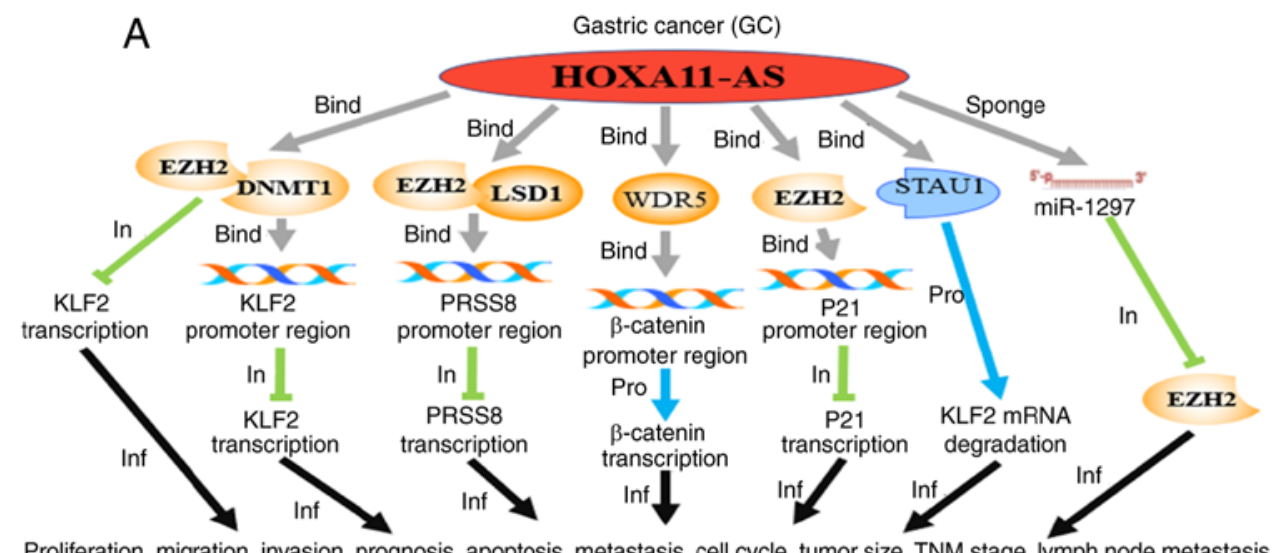

Proliferation, migration, invasion, prognosis, apoptosis, metastasis, cell cycle, tumor size, TNM stage, lymph node metastasis, EMT

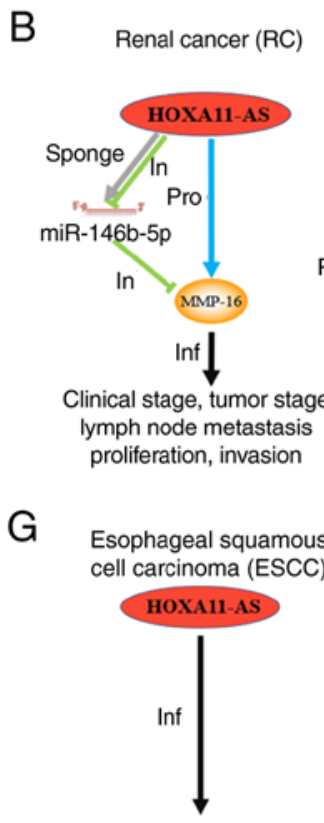

Lymph node metastasis prognosis, histological grade
C Uveal melanoma (UM)
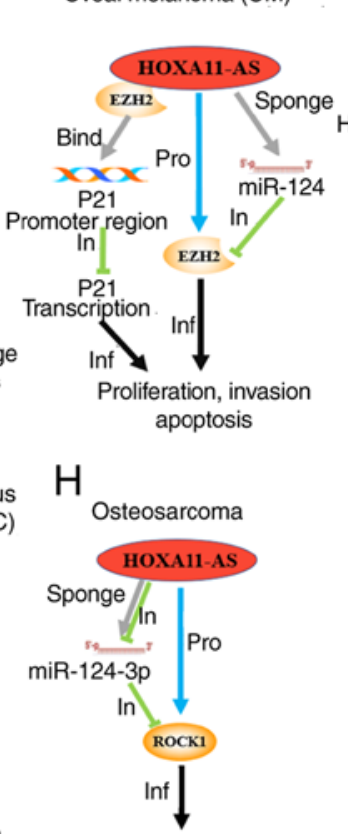

Clinical stage, distant metastasis cell cycle, proliferation invasion, prognosis
Epithelial ovarian
cancer (EOC) HOXA11-AS

An exonic variant within HOXA11-AS, rs17427875 (A>T) (HOXA11-AS minor allele T)

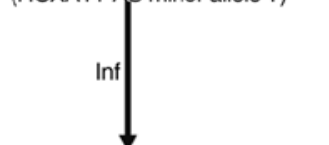

Proliferation, migration invasion

I

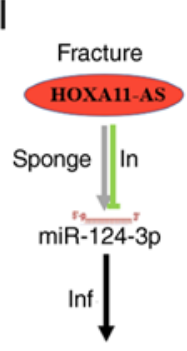

Apoptosis, proliferation
Laryngeal squamous cell
carcinoma (LSCC)
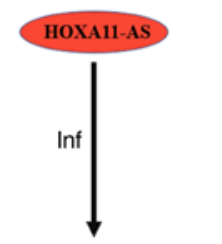

Proliferation, invasion, migration Migration prognosis, neck nodal metastasis tumor grade, prognosis, clinical stage

F Cervical cancer
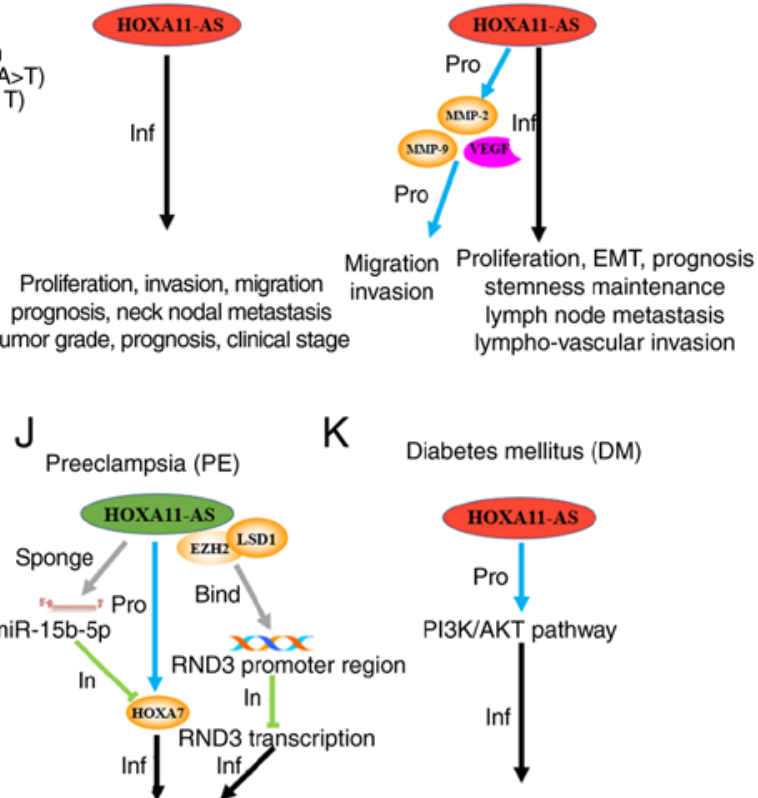

Apoptosis, cell cycle, invasion growth, migration
Apoptosis, migration
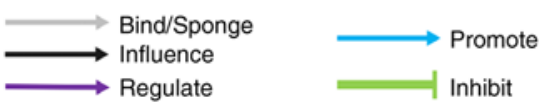

Downregulation

Figure 3. Schematic diagram, introducing in detail the molecular mechanisms, clinical values and cell phenotypes affected by HOXA11-AS in different types of tumors, including (A) GC, (B) RC, (C) UM, (D) EOC, (E) LSCC, (F) CC, (G) ESCC, (H) osteosarcoma, (I) fracture, (J) PE and (K) DM. 'Upregulation'/'downregulation' indicates that the expression level of HOXA11-AS in such a tumor was increased/decreased compared with normal tissues. The gray arrows ('bind/sponge') indicate that HOXA11-AS binds to the promoter region of a gene or, as a sponge, binds to a miRNA. The black arrows ('Inf') indicate that HOXA11-AS affects the phenotypes and the clinical characteristics of the cancer under consideration. The blue ('Pro') and green ('In') arrows indicate the promoting or inhibitory effects on the downstream genes, respectively. The purple arrows ('Reg') indicate the regulatory effects on the downstream pathway. GC, gastric cancer; RC, renal cancer; UM, uveal melanoma; EOC, epithelial ovarian cancer; LSCC, laryngeal squamous cell carcinoma; ESCC, esophageal squamous cell carcinoma; PE, pre-eclampsia; DM, diabetes mellitus; HOXA11-AS, HOXA11 antisense RNA.

led to a marked decrease in the growth, proliferation, invasion, and EMT of the ccRCC cells. Regarding the mechanism, Yang et al (118) discovered that HOXA11-AS functions as a ceRNA to suppress the expression of miR-146b-5p, which subsequently modulates the expression of its downstream target, matrix metalloproteinase-16 (MMP16) in RC. Therefore, HOXA11-AS promotes RC cell invasion and proliferation by regulating the miR-146b-5p/MMP16 pathway (Fig. 3B). During this process, HOXA11-AS may function as an oncogene in ccRCC and may therefore represent an efficient therapeutic target for RCC.

Uveal melanoma. Uveal melanoma (UM) ranks first among primary intraocular malignant tumors in adults, and the uvea ranks second among the common sites of primary melanoma $(119,120)$. The metastatic rate of UM is very high, and UM ultimately spreads to the liver in up to $50 \%$ of patients (121). Lu et al (122) discovered that HOXA11-AS is overexpressed in 
UM, and HOXA11-AS is shown to enhance the rates of UM cell proliferation and invasion, while repressing apoptosis. Authors of that study also reported that HOXA11-AS recruits $\mathrm{EZH} 2$ to the promoter region of p21 and mediates H3K27me3 to suppress its transcription. Furthermore, HOXA11-AS acts as a ceRNA for miR-124, which directly targets EZH2, and the cell proliferation and invasion-increasing effects of HOXA11-AS were attenuated upon miR-124 overexpression (Fig. 3C). Taken together, these studies indicate that HOXA11-AS has an oncogenic role through regulating the HOXA11-AS/EZH2/p21 and miR-124/EZH2 pathways in UM tumorigenesis, and HOXA11-AS may also represent a potential therapeutic target for treatment of UM.

Epithelial ovarian cancer. Ovarian malignancies are among the most commonly occurring malignancies in female reproductive organs. The most frequent ovarian malignancy type is cutaneous carcinoma, followed by malignant germ cell tumor. Among these malignant gynecological tumors, the mortality rate of epithelial ovarian cancer (EOC) is the highest, posing a serious threat to women's health (1). A large number of studies have shown that not only HOXA11-AS, but also many other IncRNAs act as oncogenes or tumor suppressor genes in different cancers. Ignarski et al (123) reported that the expression pattern of lncRNA genes is far more tissue- and cell-type specific than is the case for protein coding genes. HOXA11-AS exerts opposing effects in different types of cancer. Such expressional and functional discrepancies of HOXA11-AS in different types of cancer could be caused by distinct gene expression backgrounds in different tumors (124). For example, in EOC, HOXA11-AS can act as a tumor suppressor gene, which is different from the tumor mentioned above.

It has been reported that common germline genetic variants or single nucleotide polymorphisms (SNPs) affecting lncRNAs are conducive to the development of various types of cancer (125), such as EOC (126). Richards et al (126) reported that overexpression of HOXA11-AS results in a clear reduction in cell proliferation and survival, which are two main cellular processes associated with EOC development in both common and minor allele constructs. In particular, the existence of minor allele constructs markedly reduced the proliferation and survival of EOC cells compared with the common allele, and the expression of both alleles served to diminish cell migration and invasion. However, compared with the common allele, the minor allele exerted a more pronounced suppressive effect in both assays. Richards et al (126) found that the minor allele repressed the carcinogenic phenotypes to a greater extent compared with the common allele in EOC cells. The finding has identified a greatly decreased risk of EOC among women who have the HOXA11-AS rs17427875 T allele (126). In EOC tumor tissue, HOXA11-AS expression was reduced by over $60 \%$ on average compared with normal ovarian tissue. Richards et al (126) also found HOXA11-AS cannot exert any influence upon HOXA11 and HOXA13 (Fig. 3D). Thus, these studies suggest that HOXA11-AS may function as a tumor suppressor gene in EOC.

Laryngeal squamous cell carcinoma. Laryngeal squamous cell carcinoma (LSCC) is a commonly occurring malignant tumor of the upper respiratory tract. Laryngeal carcinoma is ranked second in terms of the most frequently occurring malignant tumors in the head and neck (127). Qu et al (128) found that the expression levels of HOXA11-AS are closely correlated with pathological grade, $\mathrm{T}$ (tumor) grade, clinical stage, neck nodal metastasis and advanced tumors of grade T3 to T4 in LSCC. Furthermore, advanced clinical stages, poor prognosis, poor differentiation and lymph node metastasis were identified in patients who expressed higher levels of HOXA11-AS. Authors of that study also found that HOXA11-AS was able to promote LSCC cell proliferation, invasion and migration (Fig. 3E). Notably, only the general effects attributable to HOXA11-AS were identified in the study of Qu et al (128), and the specific mechanism involved requires further investigation. However, their results have demonstrated that HOXA11-AS may function as an oncogene, suggesting that it is a potential novel biomarker and an efficient therapeutic target in LSCC.

Cervical cancer. It is estimated that $\mathrm{CC}$ is the fourth leading cause of cancer mortality, and ranks fourth out of the most commonly diagnosed cancers among women. In 2018, there were approximately 570,000 CC cases and 311,000 cancer-associated deaths worldwide (1). In fact, in terms of its incidence and the mortality rates, $\mathrm{CC}$ is ranked second behind BC (1). Kim et al (129) reported that the expression of HOXA11-AS is specifically upregulated in CC, and OS and 5 -year survival rates are both reduced in $\mathrm{CC}$ patients with HOXA11-AS overexpression. Cox multivariate proportional hazards analysis revealed that nodal metastasis, tumor stage, and HOXA11-AS are independent prognosticators of OS. Those authors found that HOXA11-AS is associated with enhanced cell proliferation, also leading to increased rates of cell migration and invasion in $\mathrm{CC}$. In terms of the underlying mechanism, HOXA11-AS promotes CC cell migration and invasion by upregulating the levels of MMP-9, MMP-2, and vascular endothelial growth factor (VEGF), and disordering of the EMT-associated genes suggested that HOXA11-AS may be involved in cell migration and invasion in CC (Fig. 3F). Kim et al (129) also showed that HOXA11-AS can promote activation of the genetic program that supports the cancer stem cell (CSC) phenotype and improves EMT, suggesting that HOXA11-AS may function as an oncogene in CC. Thus, HOXA11-AS may be a therapeutic target in the search for improved treatments for CC.

Esophageal squamous cell carcinoma. Among the different types of cancer, ESCC is ranked seventh in terms of its incidence and sixth in terms of overall mortality, which means that 1 out of every 20 cases of cancer-associated mortality in 2018 was estimated to have been caused by ESCC (1). Sun et al (130) found that high expression levels of HOXA11-AS are correlated with lymph node metastasis and histological grade in patients with ESCC. Compared with those patients with HOXA11-AS overexpression, patients with low HOXA11-AS expression exhibited both increased median disease-free survival (DFS) and median OS. Sun et al (130) found that lymph node metastasis and the expression of HOXA11-AS were independent poor prognosis factors in patients with ESCC (Fig. 3G). Taking all these findings into consideration, HOXA11-AS may have an oncogenic role in ESCC, and therefore HOXA11-AS may also represent a predictive marker in postoperative ESCC patients. 


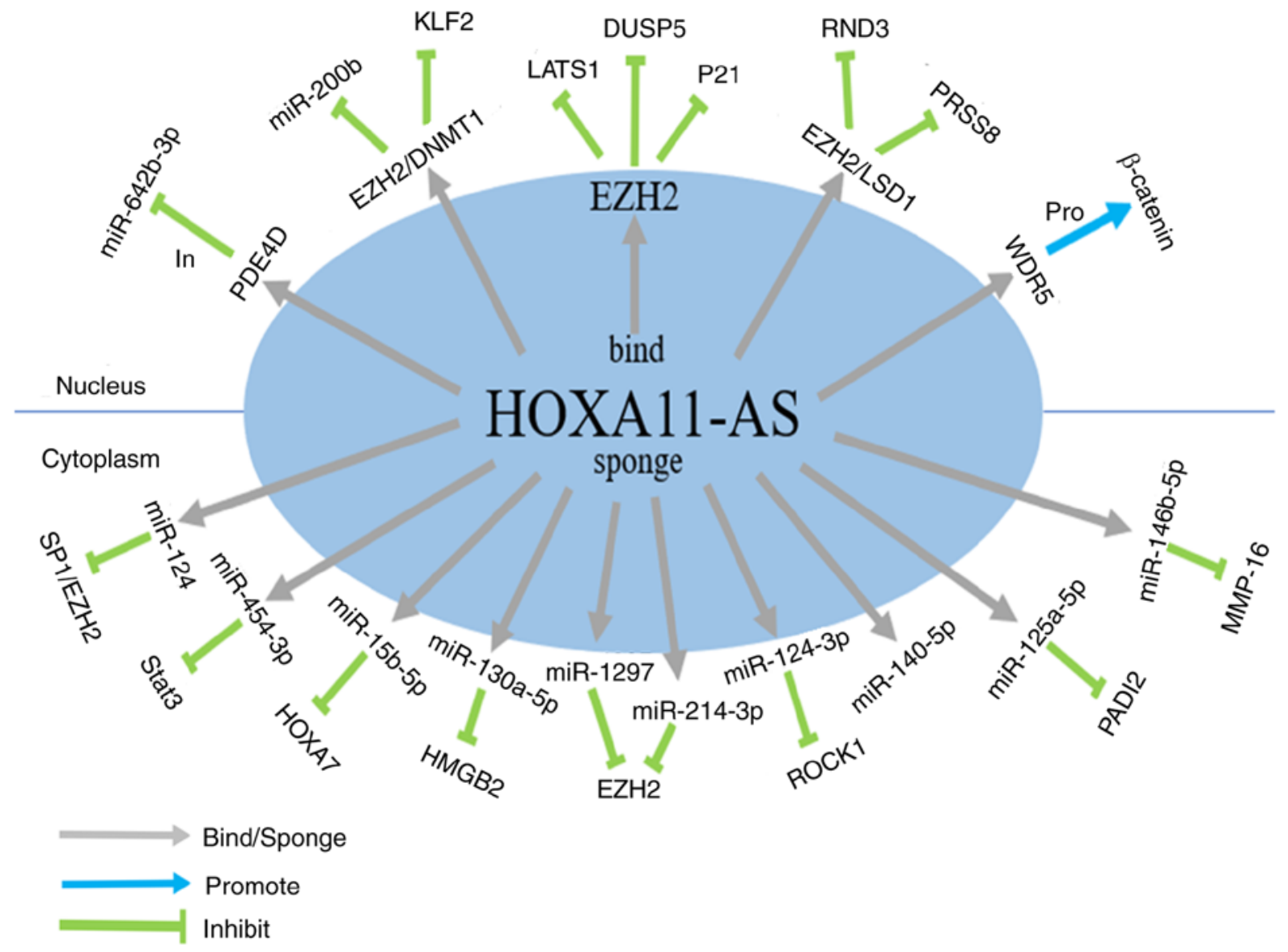

Figure 4. Schematic diagram summarizing the major molecular mechanisms of HOXA11-AS involved in different types of disease. The molecular mechanisms depicted can be divided into two categories: i) HOXA11-AS functions as molecular scaffold in the nucleus and ii) functions as ceRNA in the cytoplasm. The gray arrows ('bind'/'sponge') indicate that HOXA11-AS binds to the promoter region of genes or, as a sponge, binds to miRNAs. The blue ('Pro')/green ('In') arrows indicate the promotion or inhibition effects on the downstream genes, respectively. HOXA11-AS, HOXA11 antisense RNA.

Osteosarcoma. Osteosarcoma is ranked the first among the most commonly occurring types of primary malignant bone cancer, and is placed second in terms of cancer-associated deaths in pediatrics (131). IncRNAs are well known to be involved in the development of most tumors. Cui et al (60) found that a high level of HOXA11-AS expression is correlated with distant metastasis, reduced OS and advanced clinical stage in patients with osteosarcoma. Their study suggested that HOXA11-AS knockdown in osteosarcoma induces cell cycle arrest at the G0/G1 phase, and HOXA11-AS overexpression led to a substantial improvement in cell invasion and growth rates in osteosarcoma cells via the competitive binding of miR-124-3p, which targets Rho-associated, coiled-coil-containing protein kinase 1 (ROCK1) (Fig. 3H). In this manner, HOXA11-AS may exert oncogenic functions by regulating the miR-124-3p/ROCK1 pathway. Investigating the underlying mechanistic roles of the HOXA11-AS/miR-124-3p/ROCK1 pathway may be an important step in developing novel osteosarcoma therapeutic strategies.

\section{Other diseases}

Fracture. Given the ever-increasing aging population, fractures have become a serious health problem, constituting the most common injuries sustained worldwide. Despite the body being capable of healing fractures, many risk factors have substantially delaying effects on the process of fracture healing, including advanced age, smoking, diabetes mellitus (DM) and anti-cancer drugs (132). Therefore, it is imperative to explore the mechanisms underlying fracture healing, notably in patients with these factors, is an urgent requirement. Numerous studies have been published that demonstrate how IncRNAs are able to participate in the occurrence and development of many diseases, including fracture healing (133). Wang et al (133) found that HOXA11-AS overexpression led to a suppression of OS-732 osteoblast proliferation and improved apoptosis. In addition, HOXA11-AS can act as a ceRNA by sequestering miR-124-3p to inhibit cell proliferation and enhance apoptosis (Fig. 3I). These results may provide a novel perspective for deciphering the mechanism of fracture healing.

Preeclampsia. Preeclampsia (PE) is the leading cause of pregnancy-associated death and fetal defects (134). PE is characterized as having a blood pressure exceeding 140/90 $\mathrm{mmHg}$ from the 20th week of pregnancy onwards. Between 3 and 5\% of pregnant women experience PE, especially in developing countries (135). Xu et al (136) found that HOXA11-AS expression was markedly downregulated in pre-eclamptic placental tissues, and reducing HOXA11-AS expression led to a clear inhibition of trophoblast cell growth and migration. Mechanistically, those authors revealed that HOXA11-AS recruits LSD1 and EZH2 proteins to the RND3 gene promoter region in the nucleus to repress its expression in trophoblast 


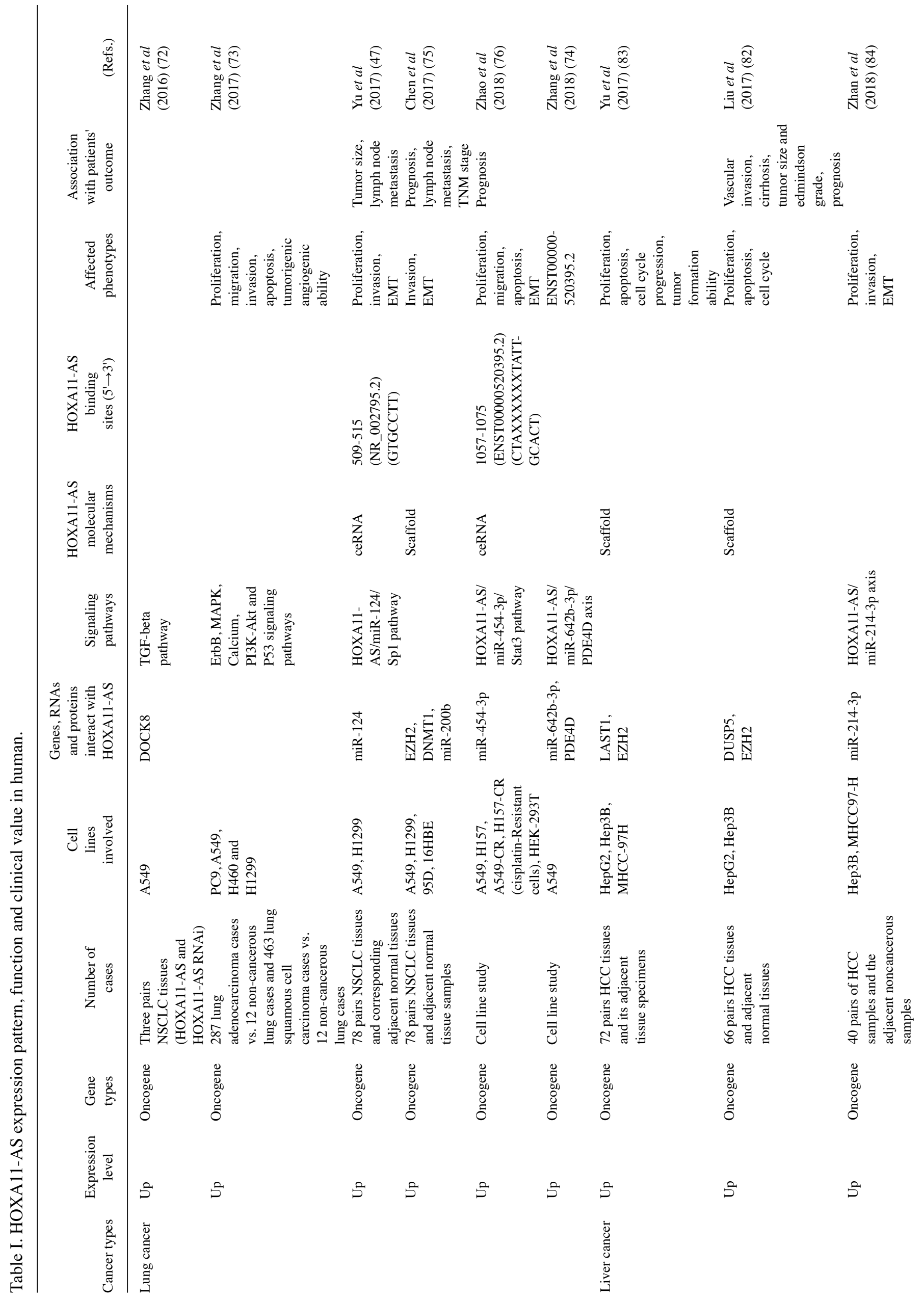




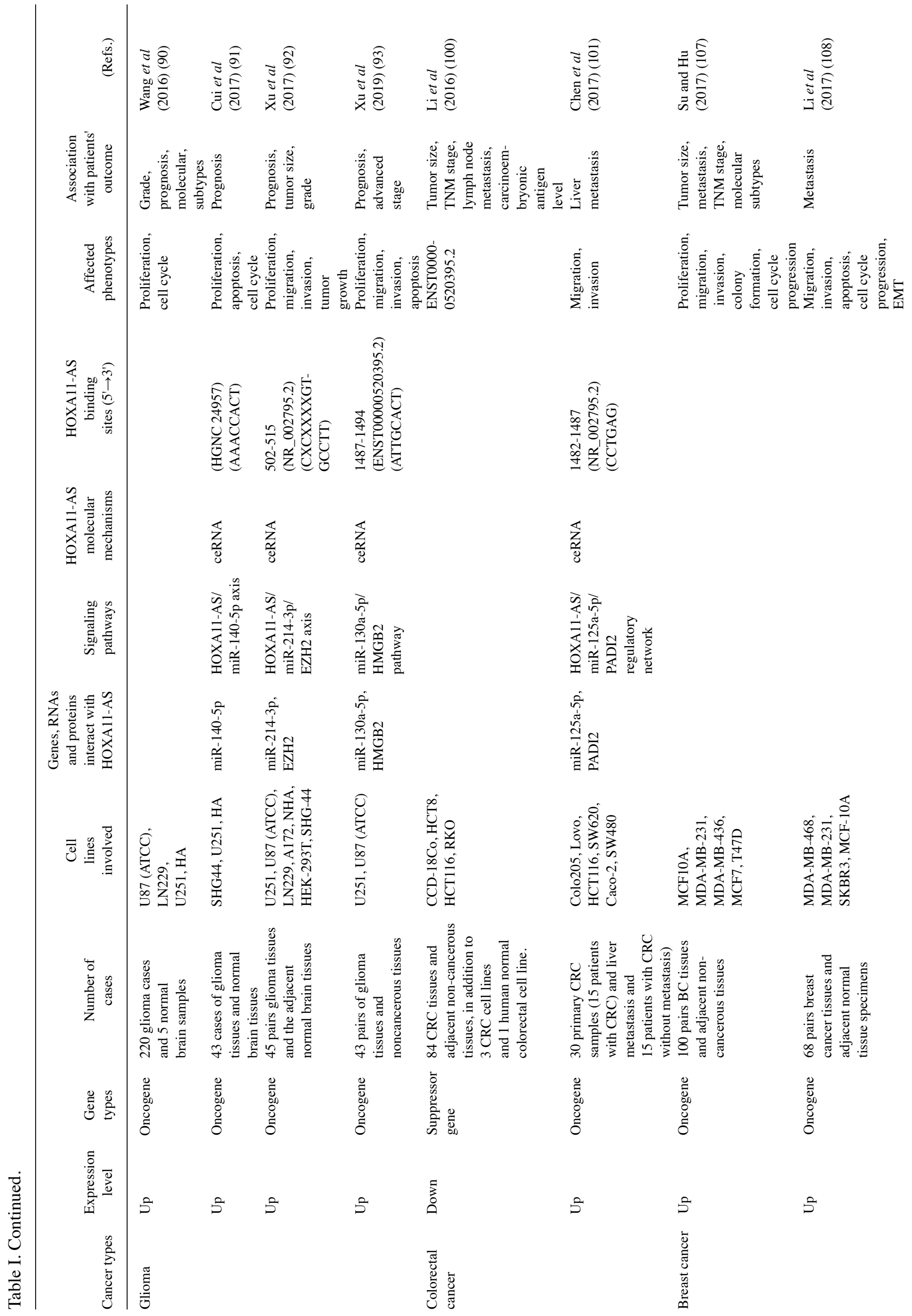




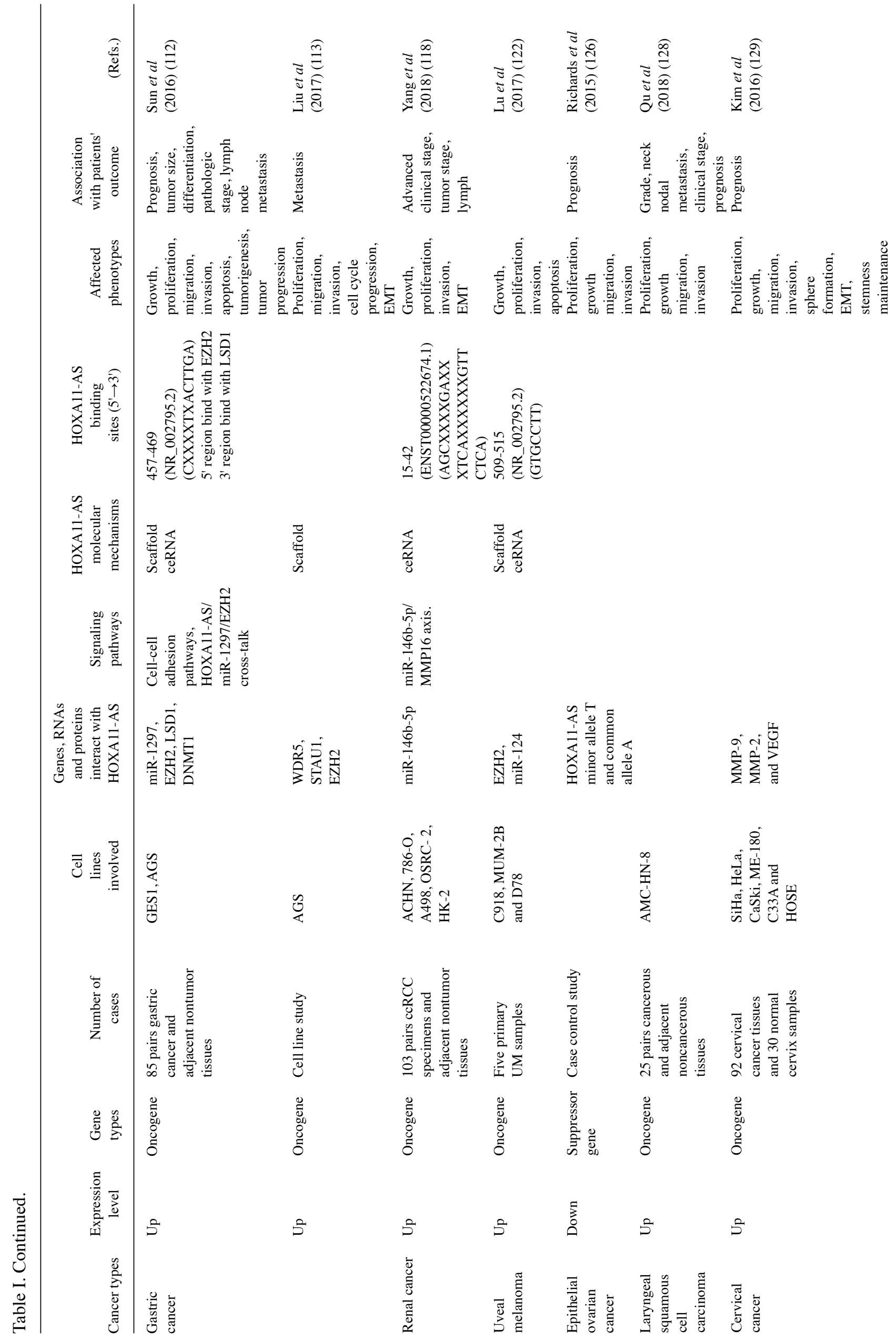


cells. When the level of HOXA11-AS expression was reduced in trophoblast cells, its ability to bind to LSD1 and EZH2 was also reduced, leading to decreased LSD1 and EZH2 binding to the RND3 gene promoter region and decreasing the inhibitory effect on RND3, which suppresses cell growth and proliferation. Furthermore, HOXA11-AS facilitated the expression of HOXA7 in the cytoplasm via sequestration of miR-15b-5p, thus exerting an influence on trophoblast proliferation (Fig. 3J). These studies revealed that HOXA11-AS may have an oncogenic function via modulating the LSD1/EZH2-RND3 and HOXA11-AS/miR-15b-5p/HOXA7 pathways. Consequently, these results have verified that abnormal expression of HOXA11-AS is involved in the occurrence and development of PE, and that this IncRNA may function as a putative target for diagnosis and treatment in PE.

Diabetes mellitus (DM). With rapid economic development and aging of the population, the number of patients with DM is increasing annually. Persistent hyperglycemia induces hyperglycemia-associated complications that pose severe medical risks, such as diabetic arteriosclerosis (DAA), atherosclerosis (AS) and cardiomyopathy (137). Studies have revealed that the incidence of cardio-cerebrovascular diseases in DM patients is markedly higher than in non-DM patients. In view of the role of lncRNAs in a variety of different tumor types and diseases, researchers have also examined the role of lncRNA in diabetes. Jin et al (138) found that expression levels of HOXA11-AS and pro-inflammatory genes were substantially increased in carotid endarterectomy specimens of DM patients, and HOXA11-AS expression was also significantly increased in the carotid arteries of DM mice. Mechanistically, HOXA11-AS knockdown reduces the expression of proliferation-associated gene (PCNA), the cell cycle-related genes $p 21$ and $p 53$, and platelet-derived growth factor $(P D G F)$-induced growth and migration of vascular smooth muscle cells (VSMCs) is repressed, significantly downregulating the expression of inflammation-associated genes in VSMCs induced by tumor necrosis factor- $\alpha$ (TNF- $\alpha$ ). Moreover, in vascular endothelial cells (VECs), low expression levels of HOXA11-AS were shown to suppress the expression of TNF- $\alpha$-induced pro-inflammatory genes and PDGF-induced vascular inflammation-related genes. Low expression levels of HOXA11-AS inhibited the PDGF-induced stimulation of the PI3K/AKT pathway by inhibiting the phosphorylation of PI3K and AKT in VSMCs and VECs (Fig. 3K). The biological functions of HOXA11-AS in DAA-induced inflammation should be further explored to identify potential new effective treatments for DAA.

\section{Conclusion}

In conclusion, an increasing number of studies have shown that lncRNAs are dysregulated in various types of cancer, and aberrant expression of IncRNAs is involved in the occurrence, development, and metastasis of cancer (139). IncRNAs function mainly by interacting with other DNA, RNA or protein molecules to exert their pre-transcriptional or post-transcriptional regulatory functions. At present, emerging in-depth studies are elucidating the regulatory effects of HOXA11-AS on a majority of different tumor types, including NSCLC, HCC and glioma, 
although its mechanisms and targets are generally found not to be similar when comparing among the different malignancies. Table I summarizes HOXA11-AS expression patterns and its functional and clinical value in different types of human cancer. Additionally, functional characteristics and molecular mechanisms of HOXA11-AS in diverse types of cancer and other diseases are summarized in Fig. 4. Although many studies have investigated HOXA11-AS, much remains to be determined before we are in a position to fully understand the mechanism of HOXA11-AS in diseases including BC, ESCC and LSCC. However, with further research, HOXA11-AS is likely to gain in importance as a novel target and guide for the prevention, diagnosis and treatment of tumors and additional diseases.

\section{Acknowledgements}

Not applicable.

\section{Funding}

This study was supported by grants (nos. 81773187 and 81572496) from the National Nature Science Foundation of China. Support was also received from the Tianjin High School Program for Young and Middle-aged Talents Backbone and the Tianjin Young Medical Talents Program.

\section{Availability of data and materials}

Not applicable.

\section{Authors' contributions}

LH and $\mathrm{YZ}$ conceived the review. $\mathrm{CW}$ and $\mathrm{LZ}$ drafted the manuscript and revised it before submission. CW and HL collected the references. All authors read and approved the final manuscript.

\section{Ethics approval and consent to participate}

Not applicable.

\section{Patient consent for publication}

Not applicable.

\section{Competing interests}

The authors declare that they have no competing interests.

\section{References}

1. Bray F, Ferlay J, Soerjomataram I, Siegel RL, Torre LA and Jemal A: Global cancer statistics 2018: GLOBOCAN estimates of incidence and mortality worldwide for 36 cancers in 185 countries. CA Cancer J Clin 68: 394-424, 2018.

2. Li J, Li Z, Zheng W, Li X, Wang Z, Cui Y and Jiang X: PANDAR: A pivotal cancer-related long non-coding RNA in human cancers. Mol Biosyst 13: 2195-2201, 2017.

3. Hu Q, Tai S and Wang J: Oncogenicity of lncRNA FOXD2-AS1 and its molecular mechanisms in human cancers. Pathol Res Pract 215: 843-848, 2019.

4. Adams BD, Parsons C, Walker L, Zhang WC and Slack FJ: Targeting noncoding RNAs in disease. J Clin Invest 127: 761-771, 2017.
5. Djebali S, Davis CA, Merkel A, Dobin A, Lassmann T, Mortazavi A, Tanzer A, Lagarde J, Lin W, Schlesinger F, et al: Landscape of transcription in human cells. Nature 489: 101-118, 2012.

6. Zhu S, Li W, Liu J, Chen CH, Liao Q, Xu P, Xu H, Xiao T, Cao Z, Peng J, et al: Genome-scale deletion screening of human long non-coding RNAs using a paired-guide RNA CRISPR-Cas9 library. Nat Biotechnol 34: 1279-1286, 2016.

7. Xue JY, Huang C, Wang W, Li HB, Sun M and Xie M: HOXA11-AS: A novel regulator in human cancer proliferation and metastasis. Onco Targets Ther 11: 4387-4393, 2018.

8. Zhao W, Ma X, Liu L, Chen Q, Liu Z, Zhang Z, Ma S, Wang Z, Li H, Wang Z and Wu J: SNHG20: A vital lncRNA in multiple human cancers. J Cell Physiol: Jan 15, 2019 (Epub ahead of print). doi: $10.1002 /$ jep.28143.

9. Schmitt AM and Chang HY: Long noncoding RNAs in cancer pathways. Cancer Cell 29: 452-463, 2016.

10. Anastasiadou E, Jacob LS and Slack FJ: Non-coding RNA networks in cancer. Nat Rev Cancer 18: 5-18, 2018.

11. Atianand MK, Caffrey DR and Fitzgerald KA: Immunobiology of long noncoding RNAs. Annu Rev Immunol 35: 177-198, 2017

12. Khorkova O, Hsiao J and Wahlestedt C: Basic biology and therapeutic implications of lncRNA. Adv Drug Deliv Rev 87: 15-24, 2015.

13. Borsani G, Tonlorenzi R, Simmler MC, Dandolo L, Arnaud D, Capra V, Grompe M, Pizzuti A, Muzny D, Lawrence C, et al: Characterization of a murine gene expressed from the inactive $\mathrm{X}$ chromosome. Nature 351: 325-329, 1991.

14. Gendrel AV and Heard E: Noncoding RNAs and epigenetic mechanisms during X-chromosome inactivation. Annu Rev Cell Dev Biol 30: 561-580, 2014.

15. Li ZX, Zhu QN, Zhang HB, Hu Y, Wang G and Zhu YS: MALAT1: A potential biomarker in cancer. Cancer Manag Res 10: 6757-6768, 2018.

16. Seiler J, Breinig M, Caudron-Herger M, Polycarpou-Schwarz M, Boutros $M$ and Diederichs S: The lncRNA VELUCT strongly regulates viability of lung cancer cells despite its extremely low abundance. Nucleic Acids Res 45: 5458-5469, 2017.

17. Ma M, Xu H, Liu G, Wu J, Li C, Wang X, Zhang S, Xu H, Ju S, Cheng W, et al: Metabolism-induced tumor activator 1 (MITA1), an Energy Stress-inducible long noncoding RNA, promotes hepatocellular carcinoma metastasis. Hepatology 70: 215-230, 2019.

18. Lu YF, Cai XL, Li ZZ, Lv J, Xiang YA, Chen JJ, Chen WJ, Sun WY, Liu XM and Chen JB: lncRNA SNHG16 functions as an oncogene by sponging MiR-4518 and Up-regulating PRMT5 expression in Glioma. Cell Physiol Biochem 45: 1975-1985, 2018.

19. Wang FW, Cao CH, Han K, Zhao YX, Cai MY, Xiang ZC, Zhang JX, Chen JW, Zhong LP, Huang Y, et al: APC-activated long noncoding RNA inhibits colorectal carcinoma pathogenesis through reduction of exosome production. J Clin Invest 129: 727-743, 2019.

20. Kim J, Piao HL, Kim BJ, Yao F, Han Z, Wang Y, Xiao Z, Siverly AN, Lawhon SE, Ton BN, et al: Long noncoding RNA MALAT1 suppresses breast cancer metastasis. Nat Genet 50: 1705-1715, 2018.

21. Zhu C, Cheng D, Qiu X, Zhuang M and Liu Z: Long noncoding RNA SNHG16 promotes cell proliferation by sponging MicroRNA-205 and upregulating ZEB1 expression in osteosarcoma. Cell Physiol Biochem 51: 429-440, 2018.

22. Yan H, Li H, Li P, Li X, Lin J, Zhu L, Silva MA, Wang X, Wang P and Zhang Z: Long noncoding RNA MLK7-AS1 promotes ovarian cancer cells progression by modulating miR-375/YAP1 axis. J Exp Clin Cancer Res 37: 237, 2018.

23. Zhuo W, Liu Y, Li S, Guo D, Sun Q, Jin J, Rao X, Li M, Sun M, Jiang M, et al: Long noncoding RNA GMAN, up-regulated in gastric cancer tissues, is associated with metastasis in patients and promotes translation of Ephrin A1 by competitively binding GMAN-AS. Gastroenterology 156: 676-691.e11, 2019.

24. Zhang E, Han L, Yin D, He X, Hong L, Si X, Qiu M, Xu T, De W, $\mathrm{Xu}$ L, et al: H3K27 acetylation activated-long non-coding RNA CCAT1 affects cell proliferation and migration by regulating SPRY4 and HOXB13 expression in esophageal squamous cell carcinoma. Nucleic Acids Res 45: 3086-3101, 2017.

25. Peng WX, Koirala P and Mo YY: lncRNA-mediated regulation of cell signaling in cancer. Oncogene 36: 5661-5667, 2017.

26. Wang Z, Yang B, Zhang M, Guo W, Wu Z, Wang Y, Jia L, Li S; Cancer Genome Atlas Research Network, Xie W and Yang D: lncRNA epigenetic landscape analysis identifies EPIC1 as an oncogenic lncRNA that interacts with MYC and promotes Cell-cycle progression in cancer. Cancer Cel 33: 706-720.e9, 2018.

27. Bhan A, Soleimani M and Mandal SS: Long noncoding RNA and cancer: A new paradigm. Cancer Res 77: 3965-3981, 2017. 
28. Chen YG, Satpathy AT and Chang HY: Gene regulation in the immune system by long noncoding RNAs. Nat Immunol 18: 962-972, 2017.

29. Kopp F and Mendell JT: Functional classification and experimental dissection of long noncoding RNAs. Cell 172: 393-407, 2018.

30. Chu C, Zhang QC, da Rocha ST, Flynn RA, Bharadwaj M, Calabrese JM, Magnuson T, Heard E and Chang HY: Systematic discovery of Xist RNA binding proteins. Cell 161: 404-416, 2015.

31. Samata $\mathrm{M}$ and Akhtar A: Dosage compensation of the $\mathrm{X}$ chromosome: A complex epigenetic assignment involving chromatin regulators and long noncoding RNAs. Annu Rev Biochem 87: 323-350, 2018

32. Vallot C, Patrat C, Collier AJ, Huret C, Casanova M, Liyakat AT, Tosolini M, Frydman N, Heard E, Rugg-Gunn PJ and Rougeulle C: XACT noncoding RNA competes with XIST in the control of $\mathrm{X}$ Chromosome activity during human early development. Cell Stem Cell 20: 102-111, 2017.

33. Furlan G, Gutierrez Hernandez N, Huret C, Galupa R van Bemmel JG, Romito A, Heard E, Morey C and Rougeulle C: The Ftx noncoding locus controls $\mathrm{X}$ chromosome inactivation independently of its RNA products. Mol Cell 70: 462-472.e8, 2018.

34. Sarma K, Cifuentes-Rojas C, Ergun A, Del Rosario A, Jeon Y, White F, Sadreyev R and Lee JT: ATRX directs binding of PRC2 to Xist RNA and Polycomb targets. Cell 159: 869-883, 2014.

35. Guttman M, Donaghey J, Carey BW, Garber M, Grenier JK, Munson G, Young G, Lucas AB, Ach R, Bruhn L, et al: lincRNAs act in the circuitry controlling pluripotency and differentiation. Nature 477: 295-300, 2011.

36. Khalil AM, Guttman M, Huarte M, Garber M, Raj A, Rivea Morales D, Thomas K, Presser A, Bernstein BE, van Oudenaarden A, et al: Many human large intergenic noncoding RNAs associate with chromatin-modifying complexes and affect gene expression. Proc Natl Acad Sci USA 106: $11667-11672,2009$.

37. Engreitz JM, Haines JE, Perez EM, Munson G, Chen J, Kane M, McDonel PE, Guttman M and Lander ES: Local regulation of gene expression by lncRNA promoters, transcription and splicing. Nature 539: 452-455, 2016.

38. Sun TT, He J, Liang Q, Ren LL, Yan TT, Yu TC, Tang JY, Bao YJ, Hu Y, Lin Y, et al: lncRNA GClncl promotes gastric carcinogenesis and may act as a modular scaffold of WDR5 and KAT2A complexes to specify the histone modification pattern. Cancer Discov 6: 784-801,2016.

39. Li D, Liu X, Zhou J, Hu J, Zhang D, Liu J, Qiao Y and Zhan Q: Long noncoding RNA HULC modulates the phosphorylation of YB-1 through serving as a scaffold of extracellular signalregulated kinase and YB-1 to enhance hepatocarcinogenesis. Hepatology 65: 1612-1627, 2017.

40. Long Y, Wang X, Youmans DT and Cech TR: How do lncRNAs regulate transcription? Sci Adv 3: eaao2110, 2017.

41. Hu WL, Jin L, Xu A, Wang YF, Thorne RF, Zhang XD and Wu M: GUARDIN is a p53-responsive long non-coding RNA that is essential for genomic stability. Nat Cell Biol 20: 492-502, 2018.

42. Bhan A and Mandal SS: Estradiol-induced transcriptional regulation of long non-coding RNA, HOTAIR. Methods Mol Biol 1366: 395-412, 2016

43. Grelet S, Link LA, Howley B, Obellianne C, Palanisamy V, Gangaraju VK, Diehl JA and Howe PH: Addendum: A regulated PNUTS mRNA to lncRNA splice switch mediates EMT and tumour progression. Nat Cell Biol 19: 1443, 2017.

44. Wu Q, Guo L, Jiang F, Li L, Li Z and Chen F: Analysis of the miRNA-mRNA-lncRNA networks in ER+ and ER-breast cancer cell lines. J Cell Mol Med 19: 2874-2887, 2015.

45. Song YX, Sun JX, Zhao JH, Yang YC, Shi JX, Wu ZH, Chen XW, Gao P, Miao ZF and Wang ZN: Non-coding RNAs participate in the regulatory network of CLDN4 via ceRNA mediated miRNA evasion. Nat Commun 8: 289, 2017.

46. Shen L, Wang Q, Liu R, Chen Z, Zhang X, Zhou P and Wang Z: lncRNA lnc-RI regulates homologous recombination repair of DNA double-strand breaks by stabilizing RAD51 mRNA as a competitive endogenous RNA. Nucleic Acids Res 46: 717-729, 2018.

47. Yu W, Peng W, Jiang H, Sha $\mathrm{H}$ and Li J: lncRNA HOXA11-AS promotes proliferation and invasion by targeting miR-124 in human non-small cell lung cancer cells. Tumour Biol 39: 1010428317721440,2017
48. Dhir A, Dhir S, Proudfoot NJ and Jopling CL: Microprocessor mediates transcriptional termination of long noncoding RNA transcripts hosting microRNAs. Nat Struct Mol Biol 22: 319-327, 2015.

49. Augoff K, McCue B, Plow EF and Sossey-Alaoui K: miR-31 and its host gene lncRNA LOC554202 are regulated by promoter hypermethylation in triple-negative breast cancer. Mol Cancer 11: 5, 2012.

50. Yu Y, Nangia-Makker P, Farhana L and Majumdar A: A novel mechanism of IncRNA and miRNA interaction: CCAT2 regulates miR-145 expression by suppressing its maturation process in colon cancer cells. Mol Cancer 16: 155, 2017.

51. Villamizar O, Chambers CB, Riberdy JM, Persons DA and Wilber A: Long noncoding RNA Saf and splicing factor 45 increase soluble Fas and resistance to apoptosis. Oncotarget 7 : 13810-13826, 2016

52. Jadaliha M, Gholamalamdari O, Tang W, Zhang Y, Petracovici A, Hao Q, Tariq A, Kim TG, Holton SE, Singh DK, et al: A natural antisense lncRNA controls breast cancer progression by promoting tumor suppressor gene mRNA stability. PLoS Genet 14: e1007802, 2018.

53. Qu L, Ding J, Chen C, Wu ZJ, Liu B, Gao Y, Chen W, Liu F, Sun W, Li XF, et al: Exosome-Transmitted lncARSR promotes sunitinib resistance in renal cancer by acting as a competing endogenous RNA. Cancer Cell 29: 653-668, 2016.

54. Rashid F, Shah A and Shan G: Long non-coding RNAs in the cytoplasm. Genomics Proteomics Bioinformatics 14: 73-80, 2016.

55. Yoon JH, Abdelmohsen K, Srikantan S, Yang X, Martindale JL, De S, Huarte $M$, Zhan M, Becker KG and Gorospe $M$ : LincRNA-p21 suppresses target mRNA translation. Mol Cell 47: 648-655, 2012.

56. Wang KC, Yang YW, Liu B, Sanyal A, Corces-Zimmerman R, Chen Y, Lajoie BR, Protacio A, Flynn RA, Gupta RA, et al: A long noncoding RNA maintains active chromatin to coordinate homeotic gene expression. Nature 472: 120-124, 2011.

57. He RZ, Luo DX and Mo YY: Emerging roles of lncRNAs in the post-transcriptional regulation in cancer. Genes Dis 6: 6-15, 2019.

58. Yu J, Han Z, Sun Z, Wang Y, Zheng M and Song C: lncRNA SLCO4A1-AS1 facilitates growth and metastasis of colorectal cancer through $\beta$-catenin-dependent Wnt pathway. J Exp Clin Cancer Res 37: 222, 2018.

59. Jiang H, Li T, Qu Y, Wang X, Li B, Song J, Sun X, Tang Y, Wan J, Yu Y, et al: Long non-coding RNA SNHG15 interacts with and stabilizes transcription factor Slug and promotes colon cancer progression. Cancer Lett 425: 78-87, 2018.

60. Cui M, Wang J, Li Q, Zhang J, Jia J and Zhan X: Long non-coding RNA HOXA11-AS functions as a competing endogenous RNA to regulate ROCK1 expression by sponging miR-124-3p in osteosarcoma. Biomed Pharmacother 92: 437-444, 2017.

61. Zheng LL, Li JH, Wu J, Sun WJ, Liu S, Wang ZL, Zhou H, Yang JH and Qu LH: deepBase v2.0: Identification, expression, evolution and function of small RNAs, lncRNAs and circular RNAs from deep-sequencing data. Nucleic Acids Res 44: D196-D202, 2016.

62. Spencer DH, Young MA, Lamprecht TL, Helton NM, Fulton R, O'Laughlin M, Fronick C, Magrini V, Demeter RT, Miller CA, et al: Epigenomic analysis of the HOX gene loci reveals mechanisms that may control canonical expression patterns in AML and normal hematopoietic cells. Leukemia 29: $1279-1289,2015$

63. Garcia-Fernández J: The genesis and evolution of homeobox gene clusters. Nat Rev Genet 6: 881-892, 2005

64. Kelly ZL, Michael A, Butler-Manuel S, Pandha HS and Morgan RG: HOX genes in ovarian cancer. J Ovarian Res 4: 16 , 2011.

65. Cheng W, Liu J, Yoshida H, Rosen D and Naora H: Lineage infidelity of epithelial ovarian cancers is controlled by HOX genes that specify regional identity in the reproductive tract. Nat Med 11: 531-537, 2005.

66. Lu S, Jiang X, Su Z, Cui Z, Fu W and Tai S: The role of the long non-coding RNA HOXA11-AS in promoting proliferation and metastasis of malignant tumors. Cell Biol Int 42: 1596-1601, 2018.

67. Lu CW, Zhou DD, Xie T, Hao JL, Pant OP, Lu CB and Liu XF HOXA11 antisense long noncoding RNA (HOXA11-AS): A promising lncRNA in human cancers. Cancer Med 7: 3792-3799, 2018

68. Xu YJ, Du Y and Fan Y: Long noncoding RNAs in lung cancer: What we know in 2015. Clin Transl Oncol 18: 660-665, 2016. 
69. Kang CG, Lee HJ, Kim SH and Lee EO: Zerumbone suppresses Osteopontin-induced cell invasion through inhibiting the FAK/AKT/ROCK pathway in human Non-small cell lung cancer A549 cells. J Nat Prod 79: 156-160, 2016.

70. Osmani L, Askin F, Gabrielson E and Li QK: Current WHO guidelines and the critical role of immunohistochemical markers in the subclassification of non-small cell lung carcinoma (NSCLC): Moving from targeted therapy to immunotherapy. Semin Cancer Biol 52: 103-109, 2018.

71. Li Y, Xuan J, Song Y, Qi W, He B, Wang P and Qin L: Nanoporous Glass integrated in volumetric Bar-chart chip for Point-of-Care diagnostics of non-small cell lung cancer. Acs Nano 10: 1640-1647, 2016.

72.Zhang Y, He RQ, Dang YW, Zhang XL, Wang X, Huang SN, Huang WT, Jiang MT, Gan XN, Xie Y, et al: Comprehensive analysis of the long noncoding RNA HOXA11-AS gene interaction regulatory network in NSCLC cells. Cancer Cell Int 16: 89, 2016.

73. Zhang Y, Chen WJ, Gan TQ, Zhang XL, Xie ZC, Ye ZH, Deng Y, Wang ZF, Cai KT, Li SK, et al: Clinical significance and effect of lncRNA HOXA11-AS in NSCLC: A study based on bioinformatics, in vitro and in vivo verification. Sci Rep 7: 5567-18, 2017.

74. Zhang Y, Luo J, Wang X, Wang HL, Zhang XL, Gan TQ, Chen G and Luo DZ: A comprehensive analysis of the predicted targets of miR-642b-3p associated with the long non-coding RNA HOXA11-AS in NSCLC cells. Oncol Lett 15: 6147-6160, 2018.

75. Chen JH, Zhou LY, Xu S, Zheng YL, Wan YF and Hu CP. Overexpression of lncRNA HOXA11-AS promotes cell epithelial-mesenchymal transition by repressing miR-200b in non-small cell lung cancer. Cancer Cell Int 17: 64, 2017.

76. Zhao X, Li X, Zhou L, Ni J, Yan W, Ma R, Wu J, Feng J and Chen P: IncRNA HOXA11-AS drives cisplatin resistance of human LUAD cells via modulating miR-454-3p/Stat3. Cancer Sci 109: 3068-3079, 2018

77. Wu F, Yin Z, Yang L, Fan J, Xu J, Jin Y, Yu J, Zhang D and Yang G: Smoking induced extracellular vesicles release and their distinct properties in Non-small cell lung cancer. J Cancer 10 3435-3443, 2019.

78. Vogel A, Cervantes A, Chau I, Daniele B, Llovet J, Meyer T, Nault JC, Neumann U, Ricke J, Sangro B, et al: Hepatocellular carcinoma: ESMO clinical practice guidelines for diagnosis treatment and follow-up. Ann Oncol 29 (Suppl 4): iv238-iv255, 2018

79. Koeberle D, Dufour JF, Demeter G, Li Q, Ribi K, Samaras P Saletti P, Roth AD, Horber D, Buehlmann M, et al: Sorafenib with or without everolimus in patients with advanced hepatocellular carcinoma (HCC): A randomized multicenter, multinational phase II trial (SAKK 77/08 and SASL 29). Ann Oncol 27: 856-861, 2016.

80. Tai WM, Yong WP, Lim C, Low LS, Tham CK, Koh TS, Ng QS, Wang WW, Wang LZ, Hartano S, et al: Ann A phase Ib study of selumetinib (AZD6244, ARRY-142886) in combination with sorafenib in advanced hepatocellular carcinoma (HCC). Ann Oncol 27: 2210-2215, 2016.

81. Ciuleanu T, Bazin I, Lungulescu D, Miron L, Bondarenko I, Deptala A, Rodriguez-Torres M, Giantonio B, Fox NL, Wissel P, et al: A randomized, double-blind, placebo-controlled phase II study to assess the efficacy and safety of mapatumumab with sorafenib in patients with advanced hepatocellular carcinoma. Ann Oncol 27: 680-687, 2016.

82.Liu B, Li J, Liu X, Zheng M, Yang Y, Lyu Q and Jin L: Long non-coding RNA HOXA11-AS promotes the proliferation HCC cells by epigenetically silencing DUSP5. Oncotarget 8: 109509-109521, 2017

83. Yu J, Hong JF, Kang J, Liao LH and Li CD: Promotion of IncRNA HOXA11-AS on the proliferation of hepatocellular carcinoma by regulating the expression of LATS1. Eur Rev Med Pharmacol Sci 21: 3402-3411, 2017.

84. Zhan M, He K, Xiao J, Liu F, Wang H, Xia Z, Duan X, Huang R, Li Y, He X, et al: lncRNA HOXA11-AS promotes hepatocellular carcinoma progression by repressing miR-214-3p. J Cell Mol Med May 15, 2018 (Epub ahead of print). doi: 10.1111/jcmm.13633

85. Gusyatiner O and Hegi ME: Glioma epigenetics: From subclassification to novel treatment options. Semin Cancer Biol 51: $50-58,2018$

86. Cohen ZR, Ramishetti S, Peshes-Yaloz N, Goldsmith M, Wohl A, Zibly Z and Peer D: Localized RNAi therapeutics of chemoresistant grade IV glioma using hyaluronan-grafted lipid-based nanoparticles. ACS Nano 9: 1581-1591, 2015.
87. Zhang KL, Han L, Chen LY, Shi ZD, Yang M, Ren Y, Chen LC, Zhang JX, Pu PY and Kang CS: Blockage of a miR-21/EGFR regulatory feedback loop augments anti-EGFR therapy in glioblastomas. Cancer Lett 342: 139-149, 2014.

88. Wang X, Wang K, Han L, Zhang A, Shi Z, Zhang K, Zhang H, Yang $\mathrm{S}, \mathrm{Pu} \mathrm{P}$, Shen $\mathrm{C}$, et al: PRDM1 is directly targeted by miR-30a-5p and modulates the Wnt/ $\beta$-catenin pathway in a Dkk1-dependent manner during glioma growth. Cancer Lett 331: 211-219, 2013

89. Gonzalez-Quarante LH, Fernández Carballal C, Agarwal V, Vargas Lopez AJ, Gil de Sagredo Del Corral OL and Sola Vendrell E: Angiocentric Glioma in an elderly patient: Case report and review of the literature. World Neurosurg 97: 755.e5-755.e10, 2017.

90. Wang Q, Zhang J, Liu Y, Zhang W, Zhou J, Duan R, Pu P, Kang $C$ and Han L: A novel cell cycle-associated lncRNA, HOXA11-AS, is transcribed from the 5-prime end of the HOXA transcript and is a biomarker of progression in glioma. Cancer Lett 373: 251-259, 2016.

91. Cui Y, Yi L, Zhao J and Jiang Y: Long Noncoding RNA HOXA11-AS functions as miRNA sponge to promote the glioma tumorigenesis through targeting miR-140-5p. DNA Cell Biol 36: 822-828, 2017.

92. Xu C, He T, Li Z, Liu H and Ding B: Regulation of HOXA11-AS/miR-214-3p/EZH2 axis on the growth, migration and invasion of glioma cells. Biomed Pharmacother 95: 1504-1513, 2017

93. Xu CH, Xiao LM, Liu Y, Chen LK, Zheng SY, Zeng EM and Li DH: The lncRNA HOXA11-AS promotes glioma cell growth and metastasis by targeting miR-130a-5p/HMGB2. Eur Rev Med Pharmacol Sci 23: 241-252, 2019.

94. Yang JX, Liu B, Yang BY and Meng Q: Long non-coding RNA homeobox (HOX) A11-AS promotes malignant progression of glioma by targeting miR-124-3p. Neoplasma 65: 505-514, 2018.

95. Ferlay J, Soerjomataram I, Dikshit R, Eser S, Mathers C, Rebelo M, Parkin DM, Forman D and Bray F: Cancer incidence and mortality worldwide: Sources, methods and major patterns in GLOBOCAN 2012. Int J Cancer 136: E359-E386, 2015.

96. Rychahou P, Haque F, Shu Y, Zaytseva Y, Weiss HL, Lee EY, Mustain W, Valentino J, Guo P and Evers BM: Delivery of RNA nanoparticles into colorectal cancer metastases following systemic administration. ACS Nano 9: 1108-1116, 2015

97. Zhang L, Cao F, Zhang G, Shi L, Chen S, Zhang Z, Zhi W and Ma T: Trends in and predictions of colorectal cancer incidence and mortality in china from 1990 to 2025 . Front Oncol 9: 98,2019.

98. Siegel R, Ma J, Zou Z and Jemal A: Cancer statistics, 2014. CA Cancer J Clin 64: 9-29, 2014

99. Lai Y, Wang C, Civan JM, Palazzo JP, Ye Z, Hyslop T, Lin J, Myers RE, Li B, Jiang B, et al: Effects of cancer stage and treatment differences on racial disparities in survival from colon cancer: A united states population-based study. Gastroenterology 150: 1135-1146, 2016.

100. Li T, Xu C, Cai B, Zhang M, Gao F and Gan J: Expression and clinicopathological significance of the lncRNA HOXA11-AS in colorectal cancer. Oncol Lett 12: 4155-4160, 2016

101. Chen D, Sun Q, Zhang L, Zhou X, Cheng X, Zhou D, Ye F, Lin $J$ and Wang W: The lncRNA HOXA11-AS functions as a competing endogenous RNA to regulate PADI 2 expression by sponging miR-125a-5p in liver metastasis of colorectal cancer. Oncotarget 8: 70642-70652, 2017.

102. Anastasiadi Z, Lianos GD, Ignatiadou E, Harissis HV and Mitsis M: Breast cancer in young women: An overview. Updates Surg 69: 313-317, 2017.

103. Zhang Y, Leonard M, Shu Y, Yang Y, Shu D, Guo P and Zhang X: Overcoming Tamoxifen resistance of human breast cancer by targeted gene silencing using multifunctional pRNA nanoparticles. Acs Nano 11: 335-346, 2017.

104. Lemler DJ, Lynch ML, Tesfay L, Deng Z, Paul BT, Wang X, Hegde P, Manz DH, Torti SV and Torti FM: DCYTB is a predictor of outcome in breast cancer that functions via iron-independent mechanisms. Breast Cancer Res 19: 25, 2017.

105. Borin TF, Arbab AS, Gelaleti GB, Ferreira LC, Moschetta MG, Jardim-Perassi BV, Iskander AS, Varma NR, Shankar A, Coimbra VB, et al: Melatonin decreases breast cancer metastasis by modulating Rho-associated kinase protein-1 expression. J Pineal Res 60: 3-15, 2016.

106. van Roosmalen W,Le Dévédec SE, Golani O,Smid M,Pulyakhina I, Timmermans AM, Look MP, Zi D, Pont C, de Graauw M, et al: Tumor cell migration screen identifies SRPK1 as breast cancer metastasis determinant. J Clin Invest 125: 1648-1664, 2015. 
107. Su J and $\mathrm{Hu} \mathrm{X}$ : Long non-coding RNA HOXA11-AS promotes cell proliferation and metastasis in human breast cancer. Mol Med Rep 16: 4887-4894, 2017.

108. Li W, Jia G, Qu Y, Du Q, Liu B and Liu B: Long Non-coding RNA (lncRNA) HOXA11-AS promotes breast cancer invasion and metastasis by regulating Epithelial-mesenchymal transition. Med Sci Monit 23: 3393-3403, 2017.

109. Wang K, Liang Q, Li X, Tsoi H, Zhang J, Wang H, Go MY, Chiu PW, Ng EK, Sung JJ and Yu J: MDGA2 is a novel tumour suppressor cooperating with DMAP1 in gastric cancer and is associated with disease outcome. Gut 65: 1619-1631, 2016.

110. Sugano K: Screening of gastric cancer in Asia. Best Pract Res Clin Gastroenterol 29: 895-905, 2015.

111. Siegel R, Naishadham D and Jemal A: Cancer statistics, 2013. CA Cancer J Clin 63: 11-30, 2013.

112. Sun M, Nie F, Wang Y, Zhang Z, Hou J, He D, Xie M, Xu L, De $W$, Wang $Z$ and Wang J: IncRNA HOXA11-AS promotes proliferation and invasion of gastric cancer by scaffolding the chromatin modification factors PRC2, LSD1, and DNMT1. Cancer Res 76: 6299-6310, 2016.

113. Liu Z, Chen Z, Fan R, Jiang B, Chen X, Chen Q, Nie F, Lu K and Sun M: Over-expressed long noncoding RNA HOXA11-AS promotes cell cycle progression and metastasis in gastric cancer. Mol Cancer 16: 82, 2017

114. Grignon DJ and Che M: Clear cell renal cell carcinoma. Clin Lab Med 25: 305-316, 2005.

115. Escudier B, Eisen T, Stadler WM, Szczylik C, Oudard S, Siebels M, Negrier S, Chevreau C, Solska E, Desai AA, et al: Sorafenib in advanced clear-cell renal-cell carcinoma. N Engl J Med 356: 125-134, 2007.

116. Torre LA, Bray F, Siegel RL, Ferlay J, Lortet-Tieulent J and Jemal A: Global cancer statistics, 2012. CA Cancer J Clin 65: 87-108, 2015.

117. Ridge CA, Pua BB and Madoff DC: Epidemiology and staging of renal cell carcinoma. Semin Intervent Radiol 31: 3-8, 2014

118. Yang FQ, Zhang JQ, Jin JJ, Yang CY, Zhang WJ, Zhang HM Zheng JH and Weng ZM: HOXA11-AS promotes the growth and invasion of renal cancer by sponging miR-146b-5p to upregulate MMP16 expression. J Cell Physiol 233: 9611-9619, 2018

119. Robertson AG, Shih J, Yau C, Gibb EA, Oba J, Mungall KL, Hess JM, Uzunangelov V, Walter V, Danilova L, et al: Integrative analysis identifies four molecular and clinical subsets in Uveal melanoma. Cancer Cell 32: 204-220 e15, 2017.

120. Moore AR, Ceraudo E, Sher JJ, Guan Y, Shoushtari AN, Chang MT, Zhang JQ, Walczak EG, Kazmi MA, Taylor BS, et al: Recurrent activating mutations of G-protein-coupled receptor CYSLTR2 in uveal melanoma. Nat Genet 48: 675-680, 2016

121. Coupland SE, Lake SL,Zeschnigk M and Damato BE: Molecular pathology of uveal melanoma. Eye (Lond) 27: 230-242, 2013.

122. Lu Q, Zhao N, Zha G, Wang H, Tong Q and Xin S: IncRNA HOXA11-AS exerts oncogenic functions by repressing p21 and miR-124 in Uveal melanoma. DNA Cell Biol 36: 837-844, 2017.

123. Ignarski M, Islam R and Müller RU: Long Non-coding RNAs in Kidney disease. Int J Mol Sci 20: E3276, 2019.

124. Dong D, Mu Z, Zhao C and Sun M: ZFAS1: A novel tumor-related long non-coding RNA. Cancer Cell Int 18: 125, 2018.

125. Cheetham SW, Gruhl F, Mattick JS and Dinger ME: Long noncoding RNAs and the genetics of cancer. Br J Cancer 108 2419-2425, 2013.
126. Richards EJ, Permuth-Wey J, Li Y, Chen YA, Coppola D, Reid BM, Lin H, Teer JK, Berchuck A, Birrer MJ, et al: A functional variant in HOXA11-AS, a novel long non-coding RNA, inhibits the oncogenic phenotype of epithelial ovarian cancer. Oncotarget 6: 34745-34757, 2015.

127. Steuer CE, El-Deiry M, Parks JR, Higgins KA and Saba NF An update on larynx cancer. CA Cancer J Clin 67: 31-50, 2017.

128. Qu L, Jin M, Yang L, Sun C, Wang P, Li Y, Tian L, Liu M and Sun Y: Expression of long non-coding RNA HOXA11-AS is correlated with progression of laryngeal squamous cell carcinoma. Am J Transl Res 10: 573-580, 2018

129. Kim HJ, Eoh KJ, Kim LK, Nam EJ, Yoon SO, Kim KH, Lee JK, Kim SW and Kim YT: The long noncoding RNA HOXA11 antisense induces tumor progression and stemness maintenance in cervical cancer. Oncotarget 7: 83001-83016, 2016.

130. Sun XY, Wang XF, Cui YB, Cao XG, Zhao RH, Wei HY, Cao W and $\mathrm{Wu} \mathrm{W}$ : Expression level and clinical significance of lncRNA HOXA11-AS in esophageal squamous cell carcinoma patients. Zhonghua Zhong Liu Za Zhi 40: 186-190, 2018 (In Chinese)

131. Jemal A, Bray F, Center MM, Ferlay J, Ward E and Forman D: Global cancer statistics. CA Cancer J Clin 61: 69-90, 2011.

132. Wang C, Inzana JA, Mirando AJ, Ren Y, Liu Z, Shen J, O'Keefe RJ, Awad HA and Hilton MJ: NOTCH signaling in skeletal progenitors is critical for fracture repair. J Clin Invest 126: 1471-1481, 2016.

133. Wang XN, Zhang LH, Cui XD, Wang MX, Zhang GY and Yu PL: lncRNA HOXA11-AS is involved in fracture healing through regulating mir-124-3p. Eur Rev Med Pharmacol Sci 21: 4771-4776, 2017.

134. Mirzakhani H, Litonjua AA, McElrath TF, O'Connor G, Lee-Parritz A, Iverson R, Macones G, Strunk RC, Bacharier LB, Zeiger R, et al: Early pregnancy vitamin D status and risk of preeclampsia. J Clin Invest 126: 4702-4715, 2016.

135. Powe CE, Levine RJ and Karumanchi SA: Preeclampsia, a disease of the maternal endothelium: The role of antiangiogenic factors and implications for later cardiovascular disease. Circulation 123: 2856-2869, 2011.

136. Xu Y, Wu D, Liu J, Huang S, Zuo Q, Xia X, Jiang Y, Wang S, Chen Y, Wang T and Sun L: Downregulated IncRNA HOXA11-AS affects trophoblast cell proliferation and migration by regulating RND3 and HOXA7 expression in PE. Mol Ther Nucleic Acids 12: 195-206, 2018.

137. Hu L, Chang L, Zhang Y, Zhai L, Zhang S, Qi Z, Yan H, Yan Y, Luo X, Zhang S, et al: Platelets express activated P2Y12 receptor in patients with diabetes mellitus. Circulation 136: 817-833, 2017

138. Jin QS, Huang LJ, Zhao TT, Yao XY, Lin LY, Teng YQ, Kim SH, Nam MS, Zhang LY and Jin YJ: HOXA11-AS regulates diabetic arteriosclerosis-related inflammation via PI3K/AKT pathway. Eur Rev Med Pharmacol Sci 22: 6912-6921, 2018.

139. Grelet S, Link LA, Howley B, Obellianne C, Palanisamy V, Gangaraju VK, Diehl JA and Howe PH: A regulated PNUTS mRNA to lncRNA splice switch mediates EMT and tumour progression. Nat Cell Biol 19: 1105-1115, 2017.

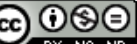

This work is licensed under a Creative Commons Attribution-NonCommercial-NoDerivatives 4.0 International (CC BY-NC-ND 4.0) License. 